OAK RIDGE

NATIONAL LABORATORY

MANAGED BY UT-BATTELLE

FOR THE DEPARTMENT OF ENERGY
Scaling of Thermal-Hydraulic Experiments for a Space Rankine Cycle and Selection of a Preconceptual Scaled Experiment Design

C. D. Sulfredge

G. L. Yoder, Jr.

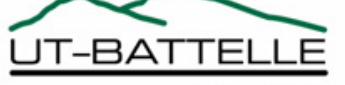




\section{DOCUMENT AVAILABILITY}

Reports produced after January 1, 1996, are generally available free via the U.S. Department of Energy (DOE) Information Bridge:

Web site: http://www.osti.gov/bridge

Reports produced before January 1, 1996, may be purchased by members of the public from the following source:

National Technical Information Service

5285 Port Royal Road

Springfield, VA 22161

Telephone: 703-605-6000 (1-800-553-6847)

TDD: 703-487-4639

Fax: 703-605-6900

E-mail: info@ntis.fedworld.gov

Web site: http://www.ntis.gov/support/ordernowabout.htm

Reports are available to DOE employees, DOE contractors, Energy Technology Data Exchange (ETDE) representatives, and International Nuclear Information System (INIS) representatives from the following source:

Office of Scientific and Technical Information

P.O. Box 62

Oak Ridge, TN 37831

Telephone: 865-576-8401

Fax: 865-576-5728

E-mail: reports@adonis.osti.gov

Web site: http://www.osti.gov/contact.html

This report was prepared as an account of work sponsored by an agency of the United States Government. Neither the United States government nor any agency thereof, nor any of their employees, makes any warranty, express or implied, or assumes any legal liability or responsibility for the accuracy, completeness, or usefulness of any information, apparatus, product, or process disclosed, or represents that its use would not infringe privately owned rights. Reference herein to any specific commercial product, process, or service by trade name, trademark, manufacturer, or otherwise, does not necessarily constitute or imply its endorsement, recommendation, or favoring by the United States Government or any agency thereof. The views and opinions of authors expressed herein do not necessarily state or reflect those of the United States Government or any agency thereof. 


\title{
SCALING OF THERMAL-HYDRAULIC EXPERIMENTS FOR A SPACE RANKINE CYCLE AND SELECTION OF A PRECONCEPTUAL SCALED EXPERIMENT DESIGN
}

\author{
C. D. Sulfredge \\ G. L. Yoder, Jr.
}

September 30, 2005

\author{
Prepared by \\ OAK RIDGE NATIONAL LABORATORY \\ Oak Ridge, Tennessee 37831-6283 \\ managed by \\ UT-BATTELLE, LLC \\ for the \\ U.S. DEPARTMENT OF ENERGY \\ under contract DE-AC05-00OR22725
}




\section{CONTENTS}

LIST OF FIGURES $\mathrm{V}$

LIST OF TABLES

vii

NOMENCLATURE

ABSTRACT

1 INTRODUCTION

1.1 General Scaling Parameters for Thermal-Hydraulic Work.

1.1.1 Fluid Property Ratios

1.1.2 Hydrodynamic Flow Parameters

1.1.3 Heat Transfer Parameters

1.1.4 Centrifugal Flow Parameters

1.2 Objectives and Scope

2. INITIAL PHASE I SCALING FROM AN ACTUAL POTASSIUM

BOILER DESIGN

2.1 Initial Scaling Results for Three Fluids ........................................................ 5

2.1.1 Water ....................................................................... 5

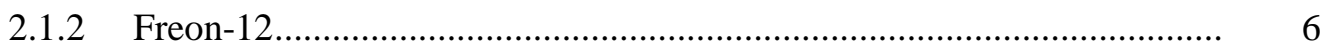

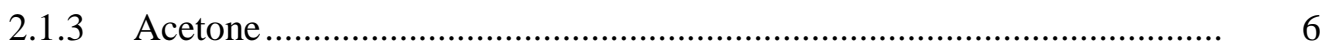

2.2 Transition to Phase II Scaling Work ........................................................................ 6

3. DESCRIPTION OF THE REVISED PHASE II SPACE RANKINE

CYCLE SYSTEM.

4. SCALING OF THE POSSIBLE BOILER DESIGNS.

System

4.1 Scaled Parameter Values for the Real Boiler System...................................... 9

4.2 General Evaluation Process for Scaled Boiler Parameters .................................. 9

4.3 Low-Pressure Scaled Boiler Solution ............................................................ 10

4.4 Higher-Pressure Scaled Boiler Solution ........................................................ 10

4.5 Additional Near-Scale Boiler Solutions at High Pressure .................................. 11

4.6 Additional Near-Scale Boiler Solutions at Low Pressure ...................................... 11

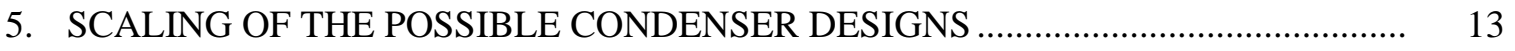

$5.1 \quad$ Derivation of HTP for Condenser Geometry ...................................................... 13

5.2 Scaled Parameter Values for the Real Condenser System.................................. 15

5.3 General Evaluation Process for Scaled Condenser Parameters ............................ 16

5.4 Low-Pressure Scaled Condenser Solution ....................................................... 17

5.5 Higher-Pressure Scaled Condenser Solution .................................................... 18

5.6 Additional Near-Scale Condenser Solutions at High Pressure ............................. 18

5.7 Additional Near-Scale Condenser Solutions at Low Pressure ............................... 19

6. SELECTION OF THE MOST PROMISING SCALED BOILER AND

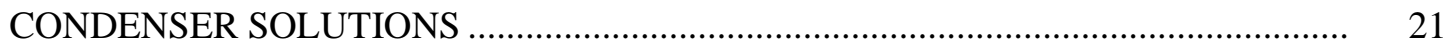

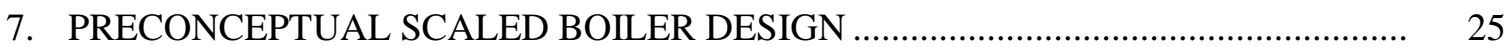

8. PRECONCEPTUAL SCALED CONDENSER DESIGN ............................................... 29

9. DESCRIPTION OF SCALED PERFLUOROHEXANE LOOP AS AN

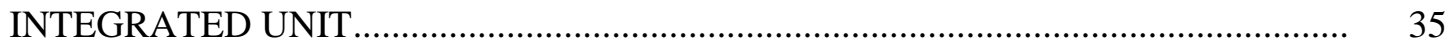

9.1 Sizing of Loop Main Condenser ....................................................................... 35

9.2 Sizing of the Loop Auxiliary Cooler and Orifice Pressure Drop......................... 35

9.3 Overall Schematic of the Scaled Perfluorohexane Loop ....................................... 35

10. ESTIMATE OF DROPLET EVAPORATION RATES IN SUPERHEATED VAPOR

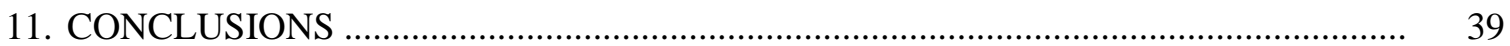

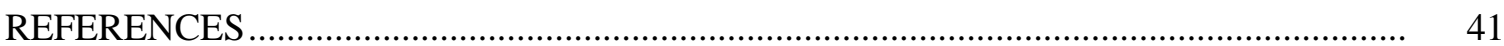




\section{LIST OF FIGURES}

Figure

Page

$1 \quad$ Schematic of the potassium boiler design chosen for scaling purposes ................. 3

2 Channel helical insert used in the original potassium boiler design ......................... 3

3 Temperature profile from potassium boiler experiment

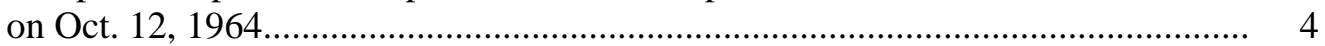

$4 \quad$ Exploded view of the actual Rankine cycle condenser.......................................... 7

$5 \quad$ Illustration of flow regimes in annular condenser ........................................... 13

$6 \quad$ Definition of terminology for condenser channel analysis ................................... 13

$7 \quad$ Differential axial volume element for analyzing condenser channel....................... 14

8 Dimensioned fabrication drawing for the preconceptual scaled

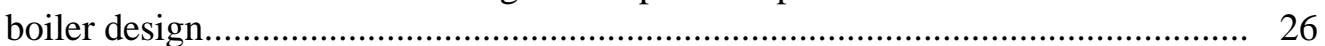

$9 \quad$ Overall pictorial drawing of the preconceptual scaled boiler design...................... 27

10 More detailed pictorial view of the scaled boiler design showing the heating shell end cap in place ............................................................................. 27

$11 \quad$ Close-up pictorial view of the scaled boiler tube and helical insert ....................... 28

12 Dimensioned fabrication drawing for the preconceptual scaled condenser design.................................................................................. $\quad 30$

13 Overall pictorial drawing of the preconceptual scaled condenser design ............... 31

14 Overall pictorial cutaway view of the scaled condenser....................................... 31

15 Pictorial view of the scaled condenser assembly at the perfluorohexane vapor inlet end

16 Cross-section pictorial view through the manifold at the perfluorohexane vapor inlet end of the scaled condenser.....

17 Cross-section pictorial view through the manifold at the perfluorohexane liquid outlet end of the scaled condenser.....

18 Pictorial illustration of the copper pipe inner condenser assembly with its helical fins

19 Illustration of the joint between the copper inner condenser pipe and the insulated plastic extension at the perfluorohexane liquid exit manifold.

20 Schematic diagram of complete scaled perfluorohexane loop experiment 


\section{LIST OF TABLES}

Table

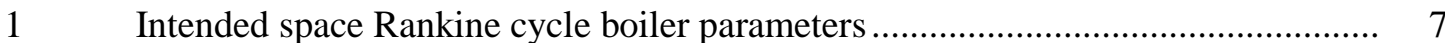

$2 \quad$ Intended space Rankine cycle condenser parameters ............................................ 8

3 Low-pressure scaled boiler design using perfluorohexane ................................... 10

$4 \quad$ Higher-pressure scaled boiler design using perfluorohexane ............................... 10

$5 \quad$ Near-scaled boiler design solutions using perfluorohexane at

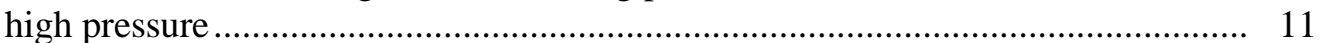

$6 \quad$ Near-scaled boiler design solutions using perfluorohexane at

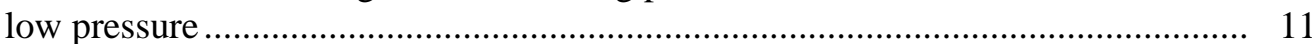

$7 \quad$ Low-pressure scaled condenser design using perfluorohexane ............................. 17

$8 \quad$ Higher-pressure scaled condenser design using perfluorohexane .......................... 18

9 Near-scaled condenser design solutions using perfluorohexane at high pressure ..................................................................................... 19

10 Near-scaled condenser design solutions using perfluorohexane at

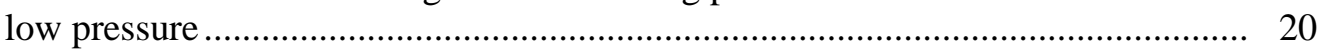

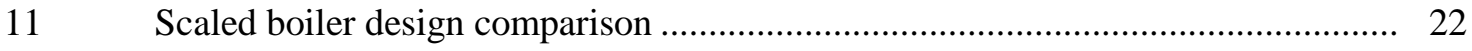

$12 \quad$ Scaled condenser design comparison............................................................. 22

13 Thermal-hydraulic parameters for the preconceptual scaled perfluorohexane boiler experiment design......................................................... 25

14 Thermal-hydraulic parameters for the preconceptual scaled perfluorohexane condenser experiment design.... 


\section{NOMENCLATURE}

\begin{tabular}{|c|c|}
\hline $\mathrm{a}$ & Condenser channel span (m) \\
\hline$A_{c}$ & Cross-sectional area $\left(\mathrm{m}^{2}\right)$ \\
\hline $\mathrm{b}$ & Condenser annulus gap (m) \\
\hline $\mathrm{Bn}$ & Bond number $\left[\mathrm{g}\left(\rho_{1}-\rho_{\mathrm{V}}\right) \mathrm{D}^{2} / \sigma\right]$ \\
\hline Bo & Boiling number $\left[\mathrm{q} " /\left(\rho \mathrm{Vh}_{\mathrm{fg}}\right)\right]$ \\
\hline$c_{p}$ & Specific heat at constant pressure $(\mathrm{J} / \mathrm{kg} \mathrm{K})$ \\
\hline$c_{\mathrm{v}}$ & Specific heat at constant volume $(\mathrm{J} / \mathrm{kg} \mathrm{K})$ \\
\hline $\mathrm{D}$ & Diameter $(\mathrm{m})$ \\
\hline $\mathrm{D}_{\mathrm{h}}$ & Channel hydraulic diameter (m) \\
\hline Fr & Froude number $\left[\mathrm{V} /(\mathrm{gD})^{1 / 2}\right]$ \\
\hline g & Acceleration of gravity $\left(\mathrm{m} / \mathrm{s}^{2}\right)$ \\
\hline $\mathrm{h}$ & Convective heat transfer coefficient $\left(\mathrm{W} / \mathrm{m}^{2} \mathrm{~K}\right)$ \\
\hline $\mathrm{h}_{\mathrm{fg}}$ & Latent heat of vaporization $(\mathrm{J} / \mathrm{kg})$ \\
\hline HTP & Heat transfer parameter $\left[k_{1} a\left(T_{\text {sat }}-T_{w}\right) L \rho_{l}\right] /\left(m_{\text {flow }} h_{f g} \rho_{v} b\right)$ \\
\hline $\mathrm{Ja}$ & Jakob number $\left[\mathrm{c}_{\mathrm{p}, 1}\left(\mathrm{~T}-\mathrm{T}_{\mathrm{sat}}\right) / \mathrm{h}_{\mathrm{fg}}\right]$ \\
\hline $\mathrm{k}$ & Thermal conductivity (W/m K) \\
\hline $\mathrm{L}$ & Length $(\mathrm{m})$ \\
\hline $\mathrm{m}$ & Mass $(\mathrm{kg})$ \\
\hline $\mathrm{m}_{\text {flow }}$ & Mass flow rate $(\mathrm{kg} / \mathrm{s})$ \\
\hline Ma & Mach number $\left(\mathrm{V} / \mathrm{V}_{\text {sonic }}\right)$ \\
\hline $\mathrm{Nu}$ & Nusselt number $\left(\mathrm{hD} / \mathrm{k}_{1}\right)$ \\
\hline $\mathrm{P}$ & Pressure $(\mathrm{Pa})$ \\
\hline $\mathrm{P} / \mathrm{D}$ & Helix pitch ratio \\
\hline $\mathrm{Pe}$ & Peclet number (RePr) \\
\hline $\operatorname{Pr}$ & Prandtl number $\left(v / \alpha_{t}\right)$ \\
\hline $\mathrm{Pw}_{\mathrm{w}}$ & Channel wetted perimeter $(\mathrm{m})$ \\
\hline q & Heat transfer rate $(\mathrm{W})$ \\
\hline q" & Heat flux $\left(\mathrm{W} / \mathrm{m}^{2}\right)$ \\
\hline r & Radial coordinate $(\mathrm{m})$ \\
\hline $\mathrm{R}$ & Radius (m) \\
\hline $\operatorname{Re}$ & Reynolds number $(\rho \mathrm{VD} / \mu)$ \\
\hline $\operatorname{Re}_{\text {rot }}$ & Rotational Reynolds number $\left\{\rho \omega \mathrm{D}^{2} / \mu=[2 \pi /(\mathrm{P} / \mathrm{D})] \operatorname{Re}\right\}$ \\
\hline $\mathrm{R}_{\mathrm{g}}$ & Ideal gas constant $(\mathrm{J} / \mathrm{kg} \mathrm{K})$ \\
\hline $\mathrm{Su}$ & Suratman number $\left(\rho_{1} \mathrm{D} \sigma / \mu_{1}^{2}=\operatorname{Re}^{2} / \mathrm{We}\right)$ \\
\hline $\mathrm{t}$ & Condenser helical fin thickness (m) \\
\hline $\mathrm{T}$ & Temperature $(\mathrm{K})$ \\
\hline V & Velocity $(\mathrm{m} / \mathrm{s})$ \\
\hline $\mathrm{We}$ & Weber number $\left(\rho \mathrm{V}^{2} \mathrm{D} / \sigma\right)$ \\
\hline $\mathrm{X}$ & Mass quality $\left(\mathrm{m}_{\mathrm{v}} / \mathrm{m}_{\text {tot }}\right)$ \\
\hline $\mathrm{z}$ & Channel axial coordinate $(\mathrm{m})$ \\
\hline $\mathrm{z}^{*}$ & Normalized axial coordinate $(\mathrm{z} / \mathrm{L})$ \\
\hline
\end{tabular}




\section{Greek Symbols}

$\begin{array}{ll}\alpha & \text { Volumetric void fraction }\left(\mathrm{A}_{\mathrm{void}} / \mathrm{A}_{\mathrm{c}}\right) \\ \alpha_{\mathrm{t}} & \text { Thermal diffusivity }\left(\mathrm{k} / \mathrm{\rho c}_{\mathrm{p}}\right) \\ \gamma & \text { Ratio of specific heats }\left(\mathrm{c}_{\mathrm{p}} / \mathrm{c}_{\mathrm{v}}\right) \\ \delta & \text { Liquid film thickness }(\mathrm{m}) \\ \theta & \text { Temperature difference variable }\left(\mathrm{T}-\mathrm{T}_{\mathrm{sat}}\right) \\ \mu & \text { Dynamic viscosity }\left(\mathrm{N} \mathrm{s} / \mathrm{m}^{2}\right) \\ \nu & \text { Kinematic viscosity }\left(\mathrm{m}^{2} / \mathrm{s}\right) \\ \rho & \text { Mass density }\left(\mathrm{kg} / \mathrm{m}^{3}\right) \\ \sigma & \text { Surface tension }(\mathrm{N} / \mathrm{m}) \\ \omega & \text { Angular velocity }\left(\mathrm{s}^{-1}\right)\end{array}$

\section{Subscripts}

$\begin{array}{ll}\text { avg } & \text { Average } \\ \text { aux } & \text { Auxiliary cooler } \\ \mathrm{i} & \text { Channel inlet conditions } \\ \mathrm{in} & \text { Refers to the inner annulus surface } \\ \mathrm{l} & \text { Liquid } \\ \mathrm{m} & \text { Mean } \\ \mathrm{main} & \text { Main condenser } \\ \mathrm{o} & \text { Channel outlet conditions } \\ \text { outer } & \text { Refers to the outer annulus surface } \\ \mathrm{r} & \text { Refers to radial position } \mathrm{r} \\ \text { sat } & \text { Saturation conditions } \\ \text { sonic } & \text { Sonic velocity conditions } \\ \text { sink } & \text { Heat sink conditions } \\ \text { tot } & \text { Total } \\ \mathrm{v} & \text { Vapor } \\ \mathrm{w} & \text { Wall } \\ \infty & \text { Surrounding environment conditions }\end{array}$




\begin{abstract}
To assist with the development of a space-based Rankine cycle power system using liquid potassium as the working fluid, a study has been conducted on possible scaled experiments with simulant fluids. This report will consider several possible working fluids and describe a scaling methodology to achieve thermal-hydraulic similarity between an actual potassium system and scaled representations of the Rankine cycle boiler or condenser. The most practical scaling approach examined is based on the selection of perfluorohexane (FC-72) as the simulant. Using the scaling methodology, a series of possible solutions have been calculated for the FC-72 boiler and condenser. The possible scaled systems will then be compared and preconceptual specifications and drawings given for the most promising design. The preconceptual design concept will also include integrating the scaled boiler and scaled condenser into a single experimental loop. All the preconceptual system specifications appear practical from a fabrication and experimental standpoint, but further work will be needed to arrive at a final experiment design.
\end{abstract}




\section{INTRODUCTION}

As part of the development program for a space-based potassium Rankine cycle power system, it will be necessary to design a scaled system with an alternate working fluid for both ground-based and flight experiments. A properly scaled experimental system will allow early testing to be performed on microgravity two-phase flow phenomena while avoiding the issues associated with conducting potassium tests on potential flight systems such as the Space Shuttle or the International Space Station (ISS).

To scale experimental test results to prototypical operating conditions, it is necessary to design the experiment using normalized parameters. Each dimensionless group represents a ratio of fluid properties, system dimensions, forces, heat transfer parameters, or some other system characteristics. If the appropriate normalized parameters have the same values for both the experimental and prototype conditions, the systems are said to exhibit geometric, dynamic, or thermal similarity. This means system dimensions, fluid flow velocity patterns, forces, and heat flows present in the experiment and prototype are related by constant scale factors. ${ }^{1}$ Thus, experimental measurements for these quantities can be extrapolated back to those expected for the full-sized system. This report will develop a procedure for carrying out the scaling calculations for such an experiment, as well as comparing several alternative solutions and working fluids for the scaled boiler and condenser. Detailed specifications will be given for the most promising preconceptual system design.

\subsection{GENERAL SCALING PARAMETERS FOR THERMAL-HYDRAULIC WORK}

The normalized parameters generally necessary for the various similarity modes of a thermal-hydraulic experiment involving two-phase flow with heat transfer have been relatively well established by many years of engineering practice and can be grouped into several categories.

\subsubsection{Fluid Property Ratios}

The primary fluid property ratios of interest are

- Prandtl number, $\operatorname{Pr}=v / \alpha_{t}$ (ratio of momentum diffusivity to thermal diffusivity)

- Density ratio, $\rho_{\mathrm{v}} / \rho_{\mathrm{l}}$ (ratio of vapor to liquid density)

- Viscosity ratio, $\mu_{\mathrm{V}} / \mu_{1}$ (ratio of vapor to liquid dynamic viscosity)

- Specific heat ratio, $c_{p, v} / c_{p, l}$ (ratio of vapor to liquid specific heat at constant pressure)

\subsubsection{Hydrodynamic Flow Parameters}

The main hydrodynamic scaling parameters governing the flow are

- Reynolds number, $\mathrm{Re}=\rho \mathrm{VD} / \mu$ (ratio of inertia forces to viscous forces)

- Peclet number, $\mathrm{Pe}=\mathrm{RePr}$

- Weber number, $\mathrm{We}=\rho \mathrm{V}^{2} \mathrm{D} / \sigma$ (ratio of inertia forces to surface tension forces)

- Mach number, $\mathrm{Ma}=\mathrm{V} / \mathrm{V}_{\text {sonic }}$ (ratio of average flow velocity to sonic velocity)

- Froude number, $\mathrm{Fr}=\mathrm{V} /(\mathrm{gD})^{1 / 2}$ (ratio of inertia forces to gravity forces)

- Bond number, $B n=g\left(\rho_{1}-\rho_{\mathrm{v}}\right) \mathrm{D}^{2} / \sigma$ (ratio of gravity force to surface tension force)

- Gravity/viscous force ratio $=\rho_{\mathrm{l}} \mathrm{g}\left(\rho_{\mathrm{l}}-\rho_{\mathrm{v}}\right) \mathrm{D}^{3} / \mu^{2}$

- Suratman number, $\mathrm{Su}=\rho_{\mathrm{l}} \mathrm{D} \sigma / \mu_{\mathrm{l}}^{2}=\mathrm{Re}^{2} / \mathrm{We}$ (ratio of surface tension forces times inertia forces to the square of the viscous forces) 


\subsubsection{Heat Transfer Parameters}

Major heat transfer scaling parameters in two-phase flow are

- Jakob number, $\mathrm{Ja}=\mathrm{c}_{\mathrm{p}, 1}\left(\mathrm{~T}-\mathrm{T}_{\mathrm{sat}}\right) / \mathrm{h}_{\mathrm{fg}}$ (ratio of sensible heat to latent heat effects)

- Boiling number, Bo $=\mathrm{q} \% /\left(\rho \mathrm{Vh}_{\mathrm{fg}}\right)$ (ratio of heat transfer to vapor formation rate)

- Quality, $X=\mathrm{m}_{\mathrm{v}} / \mathrm{m}_{\text {tot }}$

- Nusselt number, $\mathrm{Nu}=\mathrm{hD} / \mathrm{k}_{1}$ (normalized heat transfer coefficient)

\subsubsection{Centrifugal Flow Parameters}

Normalized groups related to centrifugal flow effects include

- Helix pitch $=$ P/D

- Rotational Reynolds number, $\operatorname{Re}_{\mathrm{rot}}=\rho \omega \mathrm{D}^{2} / \mu=[2 \pi /(\mathrm{P} / \mathrm{D})] \operatorname{Re}$

- Centrifugal pressure ratio $=\rho \omega^{2} \mathrm{R}^{2} /(2 \mathrm{P})$

\subsection{OBJECTIVES AND SCOPE}

Not all of these parameters can be matched simultaneously in a scaled experiment, and a degree of engineering judgment is required to obtain the best similarity possible. However, even incomplete similarity can still yield useful data about the actual system behavior. ${ }^{1}$ Fluid property ratios are especially difficult to match because of the limited choice of experimental fluids. It also is sometimes possible to compensate for these problems by adjustments to the scaled geometry or heat flux. Matching the flow hydrodynamics is particularly critical for studies involving centrifugal flow in a microgravity environment. In addition, some of the scaling parameters are not relevant under certain conditions. An example of this situation is provided by the parameters involving the gravitational acceleration, $\mathrm{g}$, which tend to go to either zero or infinity under microgravity conditions.

This study will focus on developing a scaled system addressing the boiling and condensing processes in the Rankine cycle with a different working fluid and lower power input. A properly scaled system can be designed to have the same performance characteristics as the actual system under equivalent gravity conditions. No attempt will be made to scale system performance between $0-\mathrm{g}$ and $1 \mathrm{-g}$. Furthermore, it will be assumed that the actual system is capable of operating satisfactorily in 0 -g. This assumption is consistent with the intended gravity independence of the design for the actual space Rankine cycle system. 


\section{INITIAL PHASE I SCALING FROM AN ACTUAL POTASSIUM BOILER DESIGN}

A schematic layout of Peterson's 2 potassium boiler design from the $1960 \mathrm{~s}$, used as a basis for initial scaling of a space Rankine cycle experiment, is shown in Fig. 1. Figure 2 is a close-up of the test section boiling channel with its helical insert.

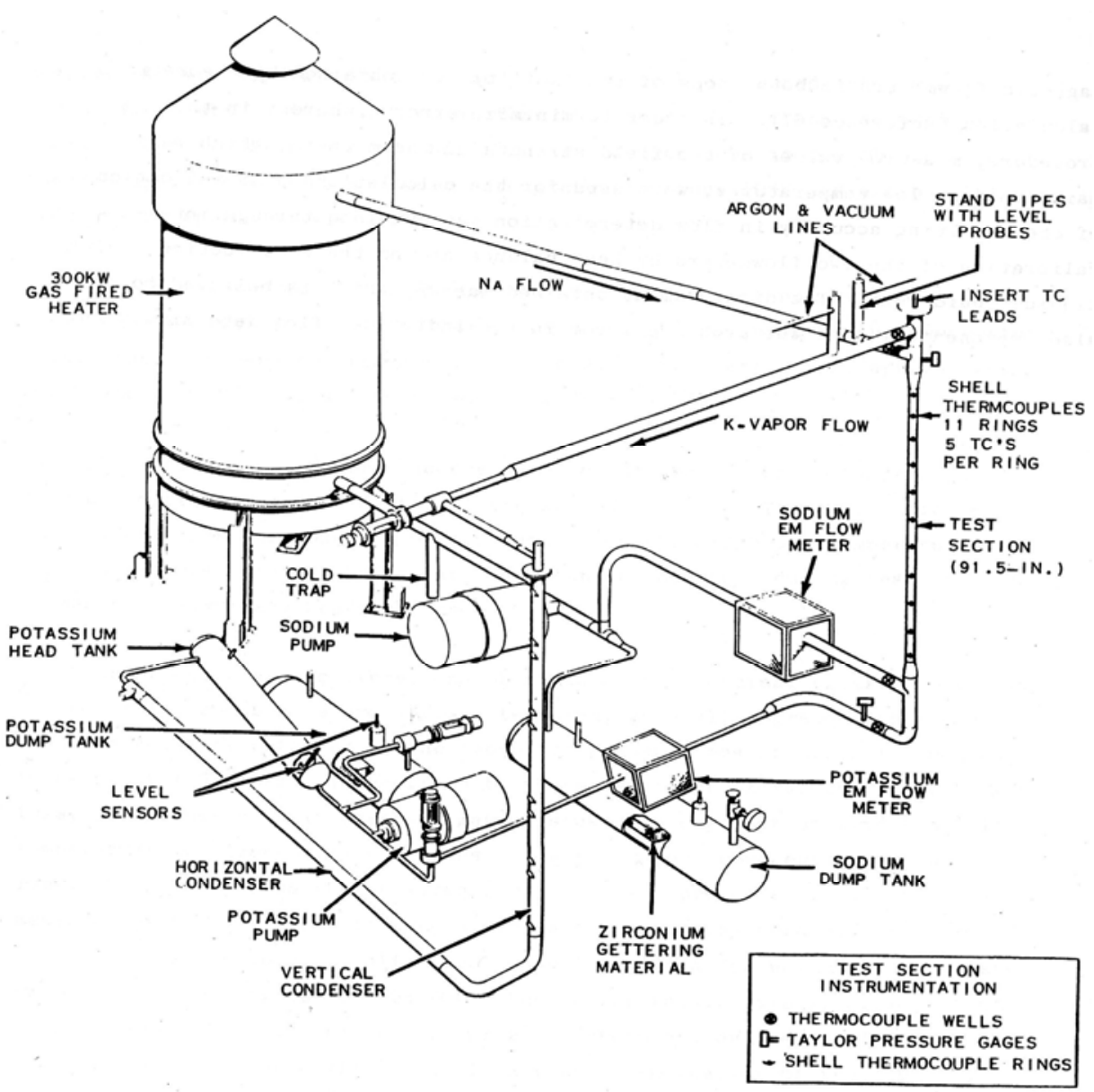

Fig. 1. Schematic of the potassium boiler design chosen for scaling purposes. Source: Ref. 2.

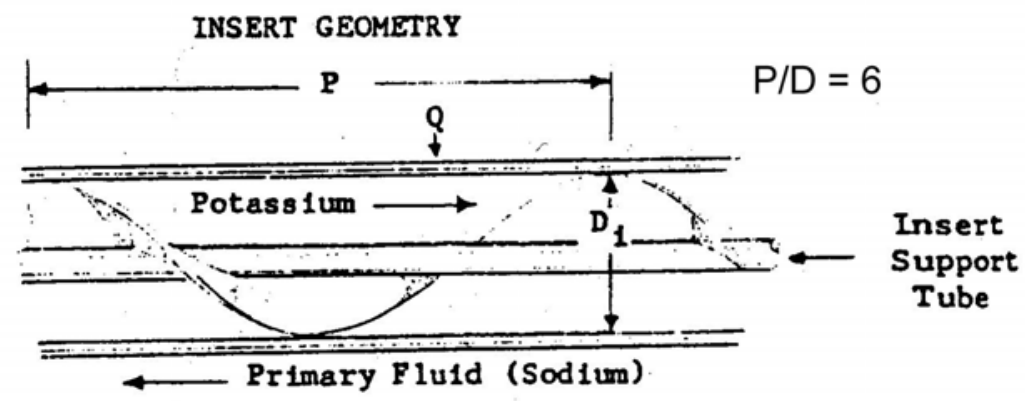

Fig. 2. Channel helical insert used in the original potassium boiler design. Source: Ref. 2. 
A plot of temperature and pressure conditions along the experimental channel for a particular run on October 12, 1964, is presented in Fig. 3. It indicates the presence of superheated potassium vapor at the channel outlet.

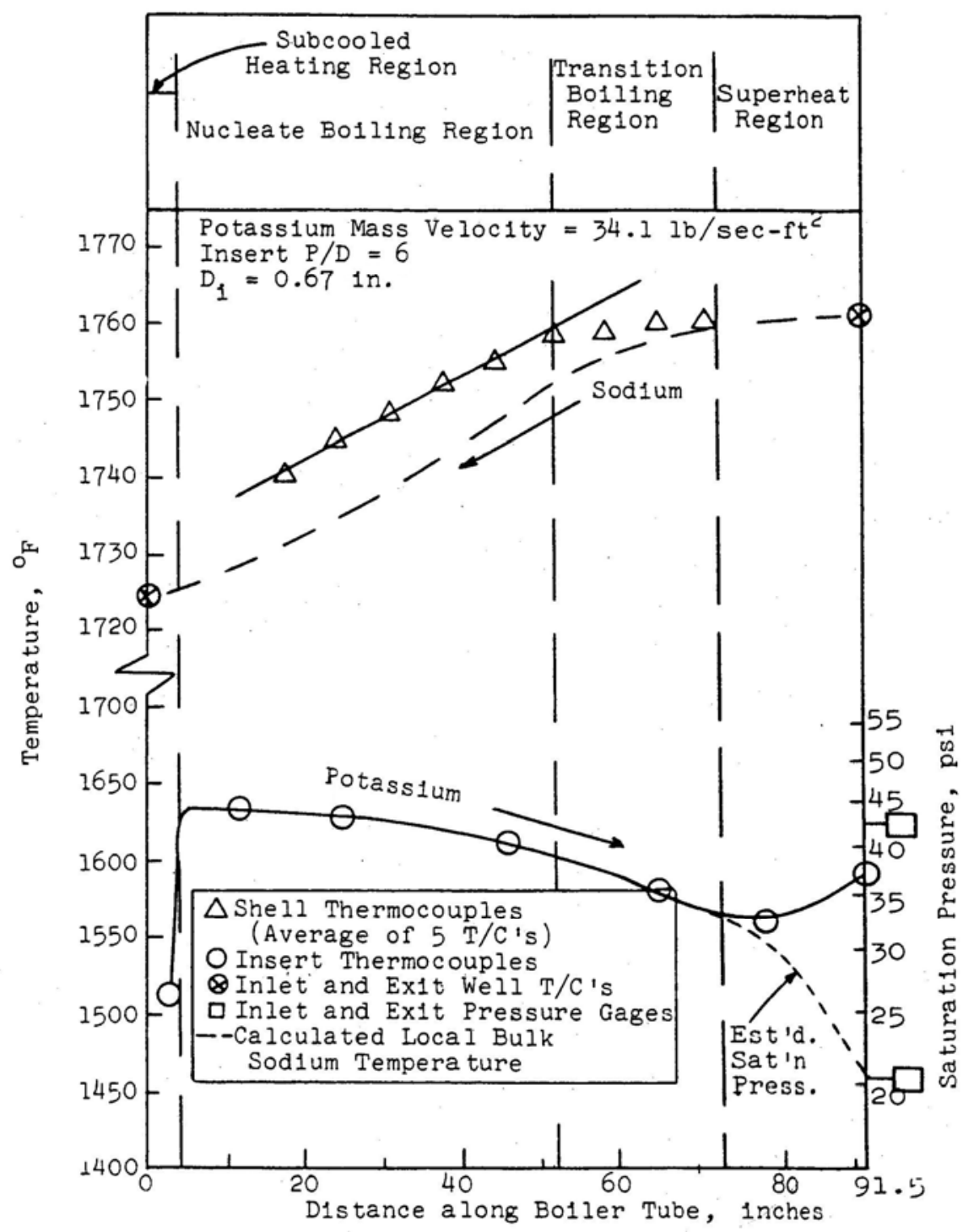

Fig. 3. Temperature profile from potassium boiler experiment on

Oct. 12, 1964. Source: Ref. 2.

The specific experimental conditions chosen for scaling purposes were taken from an experimental run that clearly resulted in superheated potassium vapor. These experimental conditions were as follows:

- Flow rate $=0.038 \mathrm{~kg} / \mathrm{s}$

- $\mathrm{T}_{\mathrm{i}}=1044.9 \mathrm{~K}$ (subcooled liquid)

- $\mathrm{T}_{\mathrm{o}}=1139.9 \mathrm{~K}$ (superheated vapor)

- Power $=62.76 \mathrm{~kW}$

- $\mathrm{P} / \mathrm{D}=6$ (helical channel insert has a pitch of 6 ) 
- $\mathrm{D}=1.70 \mathrm{~cm}$

- $\mathrm{L}=2.32 \mathrm{~m}$

- $\mathrm{V}_{\mathrm{o}}=243.8 \mathrm{~m} / \mathrm{s}$ (channel outlet flow velocity)

The corresponding values for the normalized scaling parameters that have the greatest influence on the hydrodynamic flow regimes and thermodynamics of the heat transfer processes under these conditions are

- $\mathrm{Ma}_{\mathrm{o}}=0.44$ (outlet Mach number)

- $\mathrm{Ja}_{\mathrm{i}}=-0.1617$ (inlet Jakob number)

- $\mathrm{Ja}_{\mathrm{O}}=0.0496$ (outlet Jakob number)

- $\mathrm{Re}_{\mathrm{o}}=96,277$ (outlet Reynolds number)

- $\mathrm{Re}_{\mathrm{rot}}=100,821$ (rotational Reynolds number)

\subsection{INITIAL SCALING RESULTS FOR THREE FLUIDS}

Because the sonic velocity is a material property of the fluid chosen for the experiment, fixing the outlet Mach number also determines the exit flow velocity. The specified Jakob numbers indicate the degree of subcooling or superheat at the channel inlet and outlet, respectively. Hence $\mathrm{Ja}_{\mathrm{i}}$ and $\mathrm{Ja}_{\mathrm{o}}$ help determine the temperature and pressure conditions for inlet and outlet. Matching the exit Reynolds number then gives the necessary channel diameter. Once the inlet and outlet pressures as well as the channel diameter are known, the length of the scaled channel can be determined from the pressure drop. Channel mass flow is then calculated from the diameter and average velocity, while the power requirements are obtained using the mass flow rate and enthalpy change between inlet and outlet. Finally, the rotational Reynolds number, $R_{\text {rot }}$, is used to find the channel helix pitch, P/D, for similar swirl-flow effects. The procedure just described was followed to obtain the design parameters for a scaled potassium boiler using each of three simulant test fluids.

\subsubsection{Water}

A scaled experimental system using water would have the following design parameters:

- $\mathrm{L}=2.65 \mathrm{~m}$

- $\mathrm{D}=1.75 \mathrm{~cm}$

- $\quad$ Flow rate $=0.0179 \mathrm{~kg} / \mathrm{s}$

- Power $=42.97 \mathrm{~kW}$

- $\mathrm{P} / \mathrm{D}=6$

- $\mathrm{T}_{\mathrm{i}}=20^{\circ} \mathrm{C}$ (subcooled liquid)

- $\mathrm{T}_{\mathrm{o}}=141.5^{\circ} \mathrm{C}$ (superheated vapor)

- $\mathrm{V}_{\mathrm{o}}=222 \mathrm{~m} / \mathrm{s}$

The scaling match obtained between a water system and the potassium system is excellent, with all the piping sizes and flow velocities quite comparable. However, the system power requirement of $42.97 \mathrm{~kW}$ is probably too high for a water system to be practical in the available microgravity environments. 


\subsubsection{Freon-12 (R-12)}

Freon-12 was also examined as a possible candidate fluid. Initial scaling evaluations led to the following scaled channel diameter and velocity:

- $\mathrm{D}=0.5 \mathrm{~mm}$

- $\mathrm{V}_{\mathrm{o}}=66.3 \mathrm{~m} / \mathrm{s}$

Thus, the channel diameter is unacceptably small using Freon-12 because of the high R-12 vapor density. The outlet velocity is also lower than desirable (which would largely invalidate scaling of the centrifugal flow effects for phase separation) because of the low sonic velocity in R-12 vapor. Both these problems result from the high pressures required to obtain saturation conditions in R-12 anywhere near room temperature and the high molecular weight of the experimental fluid (about $120.91 \mathrm{~kg} / \mathrm{kmol}$ for R-12).

\subsubsection{Acetone $\left(\mathrm{C}_{3} \mathrm{H}_{6} \mathrm{O}\right)$}

A scaled experimental system using acetone would have the following design parameters:

- $\mathrm{L}=1.42 \mathrm{~m}$

- $\mathrm{D}=3.6 \mathrm{~mm}$

- $\quad$ Flow rate $=2.56 \mathrm{~g} / \mathrm{s}$

- Power $=1.36 \mathrm{~kW}$

- $\mathrm{P} / \mathrm{D}=6$

- $\mathrm{T}_{\mathrm{i}}=27^{\circ} \mathrm{C}$ (subcooled liquid)

- $\mathrm{T}_{\mathrm{o}}=73.9^{\circ} \mathrm{C}$ (superheated vapor)

- $\mathrm{V}_{\mathrm{o}}=112.7 \mathrm{~m} / \mathrm{s}$

This system using acetone as the simulant fluid was the closest scaling match with moderate power input requirements that was found during the initial Phase I scoping study for a potassium boiler experiment.

\subsection{TRANSITION TO PHASE II SCALING WORK}

Flammability and toxicity concerns make acetone undesirable for use during a space mission or microgravity aircraft flight. As part of the Phase II space Rankine cycle design process, it was decided to attempt a new more detailed experiment scaling using perfluorohexane (FC-72) as the simulant fluid. Perfluorohexane is an inert, nontoxic, and nonflammable fully fluorinated Freon $\left(\mathrm{C}_{6} \mathrm{~F}_{14}\right)$. Although it has a molecular weight of $338 \mathrm{~kg} / \mathrm{kmol}$, perfluorohexane also has a low enough vapor pressure that it can be boiled near ambient conditions without excessive pressures in the system. In addition, the revised Phase II design parameters ${ }^{3}$ developed for the space Rankine cycle proved more readily adaptable to scaling with high molecular weight fluids than the Peterson experimental conditions. ${ }^{2}$ As discussed in the following sections, an excellent scaling match to the Phase II Rankine cycle system has been obtained using perfluorohexane as the working fluid. 


\section{DESCRIPTION OF THE REVISED PHASE II SPACE RANKINE CYCLE SYSTEM}

The eventual system parameters chosen for the potassium Rankine cycle in Phase II of the project differ somewhat from those of Peterson's experiment ${ }^{2}$ that were used in the initial scaling exercises. The new boiler design parameters are summarized in Table $1 .^{3}$

Compared to the Peterson experiment, this design has a smaller channel diameter and considerably tighter helix pitch, but it is only intended to generate saturated vapor (with no superheat) at the tube exit. The condenser assembly for the cycle turbine exhaust consists of an annular flow region arranged around a heat pipe for ultimate radiation of the waste heat to space. ${ }^{3}$ Like the boiler tubes, the surrounding annulus is fitted with helical fins to generate centrifugal flow and also tapers to accommodate the density changes that accompany condensation. An exploded view of the Rankine cycle condenser is shown in Fig. 4, and the corresponding condenser design parameters are given in Table 2.

Table 1. Intended space Rankine cycle boiler parameters

\begin{tabular}{|l|l|}
\hline Tube inner diameter & $1.0 \mathrm{~cm}$ \\
\hline Tube length & $233.0 \mathrm{~cm}$ \\
\hline Helix pitch ratio & $\mathrm{P} / \mathrm{D}=2$ \\
\hline Tube mass flow & $0.0227 \mathrm{~kg} / \mathrm{s}$ \\
\hline Tube inlet temperature & $885 \mathrm{~K}$ \\
\hline Tube inlet pressure & $968 \mathrm{kPa}$ \\
\hline Tube outlet temperature & $1310 \mathrm{~K}$ \\
\hline Tube outlet pressure & $773 \mathrm{kPa}$ \\
\hline Tube outlet quality & 1.00 \\
\hline Number of tubes & 12 \\
\hline
\end{tabular}

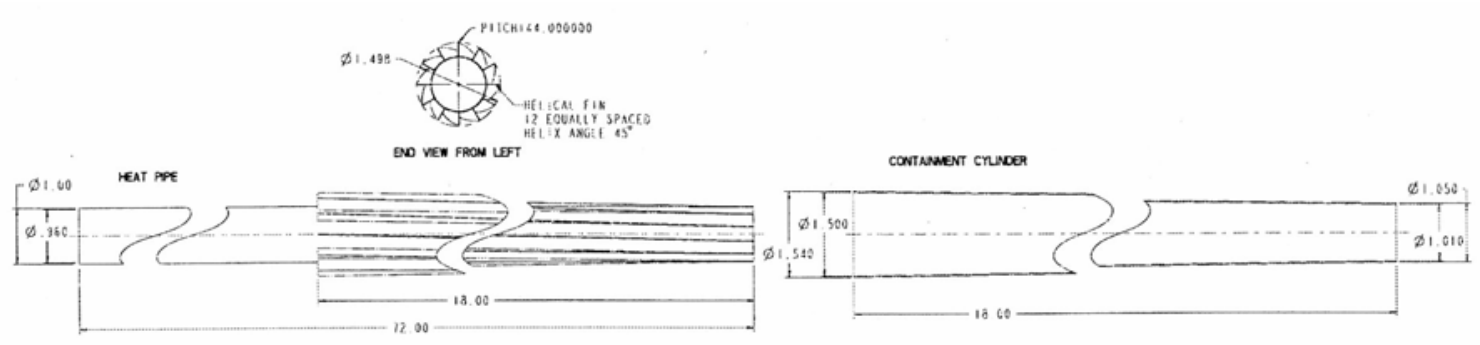

Fig. 4. Exploded view of the actual Rankine cycle condenser. Source: Ref. 3. 
Table 2. Intended space Rankine cycle condenser parameters

\begin{tabular}{|l|l|}
\hline Heat pipe (inner tube) diameter & $1.00 \mathrm{in}$. \\
\hline Outer annulus diameter (at inlet) & $1.50 \mathrm{in}$. \\
\hline Outer annulus diameter (at outlet) & $1.01 \mathrm{in}$. \\
\hline Number of helical fins & 12 \\
\hline Fin width & $0.01 \mathrm{in}$. \\
\hline Fin helix angle & $45^{\circ}$ \\
\hline Length & 18 in. \\
\hline Mass flow & $0.0025 \mathrm{~kg} / \mathrm{s}$ \\
\hline $\mathrm{T}_{\text {Sat }}-\mathrm{T}_{\mathrm{W}}$ & $1.91 \mathrm{~K}$ \\
\hline Inlet quality & 0.752 \\
\hline Outlet quality & 0.00 \\
\hline Inlet temperature & $887 \mathrm{~K}$ \\
\hline Outlet temperature & $887 \mathrm{~K}$ \\
\hline System pressure & $21.6 \mathrm{kPa}$ \\
\hline Number of tubes & 111 \\
\hline
\end{tabular}




\section{SCALING OF THE POSSIBLE BOILER DESIGNS}

\subsection{SCALED PARAMETER VALUES FOR THE REAL BOILER SYSTEM}

The most crucial normalized parameters for scaling of the boiler design are the Reynolds number at the channel exit, the Mach number at the exit, the inlet and exit Jakob numbers, and the channel insert helix pitch ratio. Evaluating these dimensionless quantities for the boiler design parameters in Table 1 yields:

- $\operatorname{Re}_{\mathrm{o}}=91449$ (outlet Reynolds number)

- $\mathrm{Ma}_{\mathrm{O}}=0.152$ (outlet Mach number)

- $\mathrm{Ja}_{\mathrm{i}}=-0.2331$ (inlet Jakob number)

- $\mathrm{Ja}_{\mathrm{O}}=0.0$ (outlet Jakob number) (saturated vapor)

- $\mathrm{P} / \mathrm{D}=2$

\subsection{GENERAL EVALUATION PROCESS FOR SCALED BOILER PARAMETERS}

One first evaluates sonic velocity in the exiting vapor using the formula

$$
\mathrm{V}_{\text {sonic }}=\left(\gamma \mathrm{R}_{\mathrm{g}} \mathrm{T}\right)^{1 / 2}
$$

and finds the exit velocity by matching the Mach number $\mathrm{Ma}_{\mathrm{o}}=\mathrm{V}_{\mathrm{O}} / \mathrm{V}_{\text {sonic }}$. Once the exit velocity has been determined from the Mach number, matching the Reynolds number, $\operatorname{Re}_{\mathrm{o}}=\rho V_{\mathrm{o}} \mathrm{D} / \mu$, yields the scaled channel diameter, $\mathrm{D}$. The helix pitch ratio, $\mathrm{P} / \mathrm{D}$, is already normalized.

Furthermore, matching both P/D and Re assures correspondence of the rotational Reynolds number $\operatorname{Re}_{\text {rot }}=[2 \pi /(\mathrm{P} / \mathrm{D})] \operatorname{Re}$ as well. Neglecting the cross-sectional area of the helical insert, the mass flow rate through the scaled channel can then be found from the equation

$$
\mathrm{m}_{\text {flow }}=(1 / 4) \pi \mathrm{D}^{2} \rho \mathrm{V}_{\mathrm{o}}
$$

The power input requirements to the scaled channel are given by

$$
\mathrm{q}_{\text {boiler }}=\mathrm{m}_{\text {flow }}\left[\mathrm{h}_{\mathrm{fg}}+\mathrm{c}_{\mathrm{p}}\left(\mathrm{T}_{\text {sat }}-\mathrm{T}_{\mathrm{i}}\right)\right] \text {. }
$$

Pressure drop through the scaled channel can also be ratioed to that in the full-sized design using

$$
\begin{aligned}
\Delta \mathrm{P}_{\text {scaled }}= & \Delta \mathrm{P}_{\text {full sized }}\left[\left(\mathrm{L}_{\text {scaled }} / \mathrm{L}_{\text {full sized }}\right)\left(\mathrm{D}_{\text {full sized }} / \mathrm{D}_{\text {scaled }}\right)\right. \\
& \left.\left(\rho_{\text {scaled }} / \rho_{\text {full sized }}\right)\left(\mathrm{V}_{\text {scaled }} / \mathrm{V}_{\text {full sized }}\right)^{2}\right]
\end{aligned}
$$

The inlet and outlet Jakob numbers, which relate the thermal-hydraulic state to saturation conditions, also place important restrictions on the system temperature and pressure. When combined with the expression for scaled channel pressure drop, specifying the Jakob numbers means that of the four temperature/pressure parameters (inlet temperature, inlet pressure, outlet temperature, and outlet pressure) only one can be selected independently. Thus, multiple scaled solutions for the perfluorohexane (FC-72) boiler experiment are possible, depending on which set of system parameters will be most convenient. 


\subsection{LOW-PRESSURE SCALED BOILER SOLUTION}

One obvious possibility is to minimize the pressure within the scaled system by setting the boiler tube exit pressure at atmospheric conditions (101.3 $\mathrm{kPa}$ or $14.7 \mathrm{psi})$. Under this assumption, one calculates the scaled boiler parameters given in Table 3 using the methods outlined in Sect. 4.2.

Table 3. Low-pressure scaled boiler design using perfluorohexane

\begin{tabular}{|l|l|}
\hline Tube inner diameter & $6.06 \mathrm{~mm}(0.239 \mathrm{in})$. \\
\hline Tube length & $91.44 \mathrm{~cm}(36.0 \mathrm{in})$. \\
\hline Helix pitch ratio & $\mathrm{P} / \mathrm{D}=2$ \\
\hline Tube mass flow & $5.01 \mathrm{~g} / \mathrm{s}$ \\
\hline Power input & $497.01 \mathrm{~W}$ \\
\hline Inlet temperature & $43.5^{\circ} \mathrm{C}$ \\
\hline Inlet pressure & $117.18 \mathrm{kPa}(17.0 \mathrm{psi})$ \\
\hline Outlet temperature & $57.0^{\circ} \mathrm{C}$ \\
\hline Outlet pressure & $101.3 \mathrm{kPa}(14.7 \mathrm{psi})$ \\
\hline Flow outlet velocity & $15.7 \mathrm{~m} / \mathrm{s}(51.54 \mathrm{ft} / \mathrm{s})$ \\
\hline Tube pressure drop & $16.13 \mathrm{kPa}(2.34 \mathrm{psi})$ \\
\hline Outlet quality & 1.00 \\
\hline
\end{tabular}

The heat input of $497.01 \mathrm{~W}$ to the scaled boiler tube can be supplied either by resistive heating of the channel wall or by transfer from a hotter secondary fluid loop.

\subsection{HIGHER-PRESSURE SCALED BOILER SOLUTION}

Another alternative is to increase the temperatures in the boiler so that the ultimate system heat sink in the condenser can be cooled by a liquid near room temperature, allowing a more convenient experiment. In this case, there will also be a corresponding increase in the system pressure. The exit temperature chosen as a basis for the higher-pressure boiler design is $90.0^{\circ} \mathrm{C}$. All the calculated design parameters for a scaled boiler tube using these higher-pressure conditions are given in Table 4.

Table 4. Higher-pressure scaled boiler design using perfluorohexane

\begin{tabular}{|l|l|}
\hline Tube inner diameter & $2.18 \mathrm{~mm}(0.086 \mathrm{in})$. \\
\hline Tube length & $30.48 \mathrm{~cm}(12.0 \mathrm{in})$. \\
\hline Helix pitch ratio & $\mathrm{P} / \mathrm{D}=2$ \\
\hline Tube mass flow & $1.96 \mathrm{~g} / \mathrm{s}$ \\
\hline Power input & $169.25 \mathrm{~W}$ \\
\hline Inlet temperature & $79.5^{\circ} \mathrm{C}$ \\
\hline Inlet pressure & $310.87 \mathrm{kPa}(45.1 \mathrm{psi})$ \\
\hline Outlet temperature & $90.0^{\circ} \mathrm{C}$ \\
\hline Outlet pressure & $276.40 \mathrm{kPa}(40.1 \mathrm{psi})$ \\
\hline Flow outlet velocity & $14.56 \mathrm{~m} / \mathrm{s}(47.75 \mathrm{ft} / \mathrm{s})$ \\
\hline Tube pressure drop & $34.60 \mathrm{kPa}(5.02 \mathrm{psi})$ \\
\hline Outlet quality & 1.00 \\
\hline
\end{tabular}


This design is also considerably more compact $(\mathrm{L}=12.0 \mathrm{in}$. vs $36.0 \mathrm{in}$.) and has only $34 \%$ of the input power requirements compared to the low-pressure scaled boiler solution.

\subsection{ADDITIONAL NEAR-SCALE BOILER SOLUTIONS AT HIGH PRESSURE}

As an alternative to using the small boiler tube calculated in Sect. 4.4 while retaining a heat sink near room temperature, high-pressure scaling solutions were developed with the boiler tube increased to 0.25 in., 0.375 in., and 0.5 in. in diameter. These results for the scaled boiler parameters are summarized in Table 5. Specifying tube diameters larger than the 0.086 in. $(2.18 \mathrm{~mm})$ from Sect. 4.4 means that the exit Reynolds and Mach numbers cannot be matched simultaneously. Instead of its true value of 0.152 , the scaled system Mach numbers range from 0.052 for the 0.25 -in. diameter boiler down to 0.026 for the 0.5 in. boiler tube. As seen in Table 5 , the scaled boiler power requirements increase considerably with greater tube diameter.

Table 5. Near-scaled boiler design solutions using perfluorohexane at high pressure

\begin{tabular}{|l|l|l|l|}
\hline Tube inner diameter & $6.35 \mathrm{~mm}(0.25 \mathrm{in})$. & $9.53 \mathrm{~mm}(0.375 \mathrm{in})$. & $12.7 \mathrm{~mm}(0.5 \mathrm{in})$. \\
\hline Tube length & $60.96 \mathrm{~cm}(24.0 \mathrm{in})$. & $60.96 \mathrm{~cm}(24.0 \mathrm{in})$. & $60.96 \mathrm{~cm}(24.0 \mathrm{in})$. \\
\hline Helix pitch ratio & P/D $=2$ & P/D $=2$ & P/D $=2$ \\
\hline Tube mass flow & $5.70 \mathrm{~g} / \mathrm{s}$ & $8.56 \mathrm{~g} / \mathrm{s}$ & $11.39 \mathrm{~g} / \mathrm{s}$ \\
\hline Power input & $518.64 \mathrm{~W}$ & $782.73 \mathrm{~W}$ & $1041.51 \mathrm{~W}$ \\
\hline Inlet temperature & $75.4^{\circ} \mathrm{C}$ & $75.0^{\circ} \mathrm{C}$ & $74.7^{\circ} \mathrm{C}$ \\
\hline Inlet pressure & $279.23 \mathrm{kPa}(40.51 \mathrm{psi})$ & $277.23 \mathrm{kPa}(40.22 \mathrm{psi})$ & $276.75 \mathrm{kPa}(40.15 \mathrm{psi})$ \\
\hline Outlet temperature & $90.0^{\circ} \mathrm{C}$ & $90.0^{\circ} \mathrm{C}$ & $90.0^{\circ} \mathrm{C}$ \\
\hline Outlet pressure & $276.40 \mathrm{kPa}(40.1 \mathrm{psi})$ & $276.40 \mathrm{kPa}(40.1 \mathrm{psi})$ & $276.40 \mathrm{kPa}(40.1 \mathrm{psi})$ \\
\hline Flow outlet velocity & $5.00 \mathrm{~m} / \mathrm{s}(16.40 \mathrm{ft} / \mathrm{s})$ & $3.34 \mathrm{~m} / \mathrm{s}(10.96 \mathrm{ft} / \mathrm{s})$ & $2.50 \mathrm{~m} / \mathrm{s}(8.20 \mathrm{ft} / \mathrm{s})$ \\
\hline Tube pressure drop & $2.81 \mathrm{kPa}(0.407 \mathrm{psi})$ & $0.834 \mathrm{kPa}(0.121 \mathrm{psi})$ & $0.352 \mathrm{kPa}(0.051 \mathrm{psi})$ \\
\hline Outlet quality & 1.00 & 1.00 & 1.00 \\
\hline
\end{tabular}

\subsection{ADDITIONAL NEAR-SCALE BOILER SOLUTIONS AT LOW PRESSURE}

Two other near-scale solutions were calculated for larger boiler tube diameters at lowpressure conditions (atmospheric pressure at the boiler outlet). These options for the scaled boiler design parameters are given in Table 6 and include both 0.375 -in. and 0.5 -in. boiler tube sizes. As was the case at higher pressure, it was not possible to maintain the true scale Mach number of 0.152 at these larger tube diameters. However, the decrease in Mach number that accompanied the larger diameters was not nearly as pronounced, with a Mach number of 0.09 at the exit of the 0.375 -in. boiler and 0.068 for the exit of the 0.5 -in. design.

Table 6. Near-scaled boiler design solutions using perfluorohexane at low pressure

\begin{tabular}{|l|l|l|}
\hline Tube inner diameter & $9.53 \mathrm{~mm}(0.375 \mathrm{in})$. & $12.7 \mathrm{~mm}(0.5 \mathrm{in})$. \\
\hline Tube length & $60.96 \mathrm{~cm}(24.0 \mathrm{in})$. & $60.96 \mathrm{~cm}(24.0 \mathrm{in})$. \\
\hline Helix pitch ratio & $\mathrm{P} / \mathrm{D}=2$ & $\mathrm{P} / \mathrm{D}=2$ \\
\hline Tube mass flow & $7.88 \mathrm{~g} / \mathrm{s}$ & $10.50 \mathrm{~g} / \mathrm{s}$ \\
\hline Power input & $817.29 \mathrm{~W}$ & $1092.40 \mathrm{~W}$ \\
\hline Inlet temperature & $39.3^{\circ} \mathrm{C}$ & $39.0^{\circ} \mathrm{C}$ \\
\hline Inlet pressure & $103.22 \mathrm{kPa}(14.975 \mathrm{psi})$ & $102.12 \mathrm{kPa}(14.816 \mathrm{psi})$ \\
\hline Outlet temperature & $57.0^{\circ} \mathrm{C}$ & $57.0^{\circ} \mathrm{C}$ \\
\hline Outlet pressure & $101.3 \mathrm{kPa}(14.7 \mathrm{psi})$ & $101.3 \mathrm{kPa}(14.7 \mathrm{psi})$ \\
\hline Flow outlet velocity & $8.25 \mathrm{~m} / \mathrm{s}(27.07 \mathrm{ft} / \mathrm{s})$ & $6.19 \mathrm{~m} / \mathrm{s}(20.31 \mathrm{ft} / \mathrm{s})$ \\
\hline Tube pressure drop & $1.896 \mathrm{kPa}(0.275 \mathrm{psi})$ & $0.800 \mathrm{kPa}(0.116 \mathrm{psi})$ \\
\hline Outlet quality & 1.00 & 1.00 \\
\hline
\end{tabular}




\section{SCALING OF THE POSSIBLE CONDENSER DESIGNS}

As described in Sect. 3, the Rankine cycle condenser consists of an annular space fitted with 12 helical fins and with the outer diameter tapering downward from the inlet to the exit. To scale this situation, it is useful to define a new dimensionless number that will be called the heat transfer parameter (HTP) for the condenser.

\subsection{DERIVATION OF HTP FOR CONDENSER GEOMETRY}

Fredley and Braun ${ }^{4}$ provide an excellent discussion of the flow regimes to be expected in such an annular condenser geometry with helical inserts. Figure 5, taken from their paper, ${ }^{4}$ shows that condensation will take place in wedge-shaped channels separated by the helical fins. The hydraulic regime inside each channel is annular flow, with most of the heat transfer taking place across the liquid layer at the channel bottom (at the inner radius of the condenser annulus). Figure 6 illustrates a cross section of one channel with the dimensions labeled to define terminology for the geometry. As the flow proceeds along the condenser, the condensate layer thickness, $\delta$, increases until the annular vapor space disappears and the channel is completely filled with liquid.

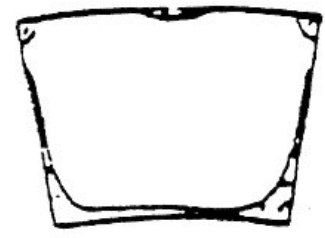

MCAOG

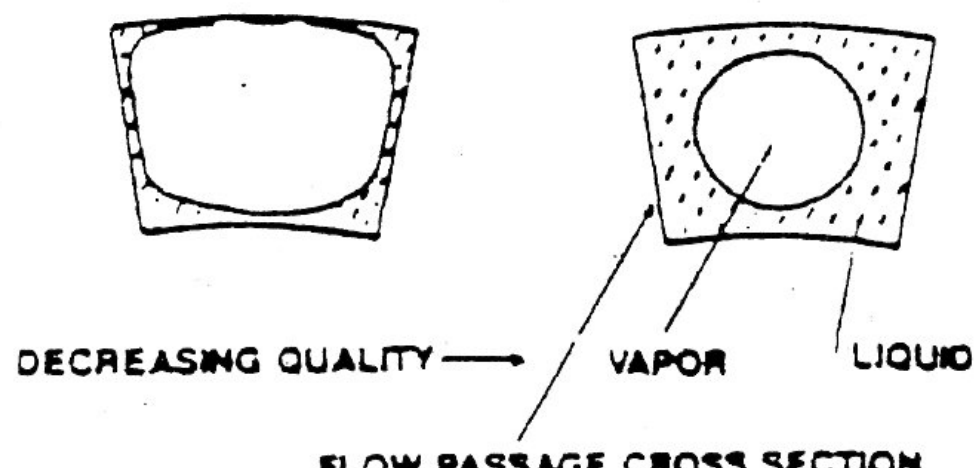

FLOW PASSAGE CAOSS SECTION

Fig. 5. Illustration of flow regimes in annular condenser. Source: Ref. 4.

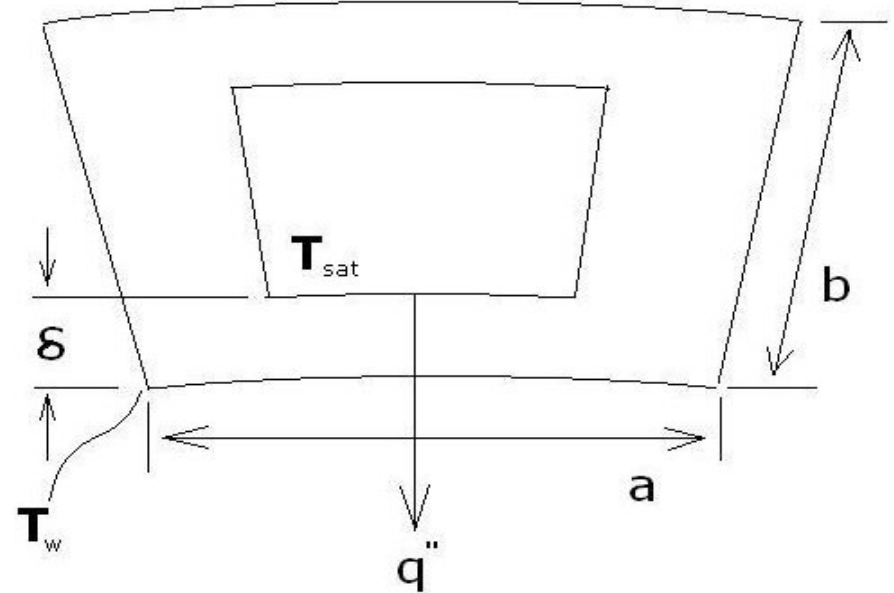

Fig. 6. Definition of terminology for condenser channel analysis. 
Figure 7 presents an idealized differential element of length dz along a condenser channel located at axial coordinate position z. By applying an energy balance to this differential volume, it is possible to relate the change in flow quality with $\mathrm{z}$ to the rate of heat conduction across the condensate layer of thickness $\delta$. The condensation rate calculation is based on heat transfer from the vapor by pure conduction across the liquid layer at the inner surface because of the low fluid flow velocities involved. Also, no attempt will be made to account for area reduction of the inner heat transfer surface as liquid accumulates along the channel sidewalls. Hence,

$$
\mathrm{m}_{\text {flow }}(\mathrm{dX} / \mathrm{dz})=-\left[\mathrm{k}_{\mathrm{l}} \mathrm{a}\left(\mathrm{T}_{\mathrm{sat}}-\mathrm{T}_{\mathrm{w}}\right)\right] /\left(\mathrm{h}_{\mathrm{fg}} \delta\right) .
$$

The quality $\mathrm{X}$ is already dimensionless, and it is possible to normalize the axial coordinate by defining $\mathrm{z}^{*}=\mathrm{z} / \mathrm{L}$, where $\mathrm{L}$ is the condenser channel length.

$$
\mathrm{dX} / \mathrm{dz}^{*}=-\left[\mathrm{k}_{\mathrm{l}} \mathrm{a}\left(\mathrm{T}_{\mathrm{sat}}-\mathrm{T}_{\mathrm{w}}\right) \mathrm{L}\right] /\left(\mathrm{m}_{\mathrm{flow}} \mathrm{h}_{\mathrm{fg}} \delta\right) .
$$

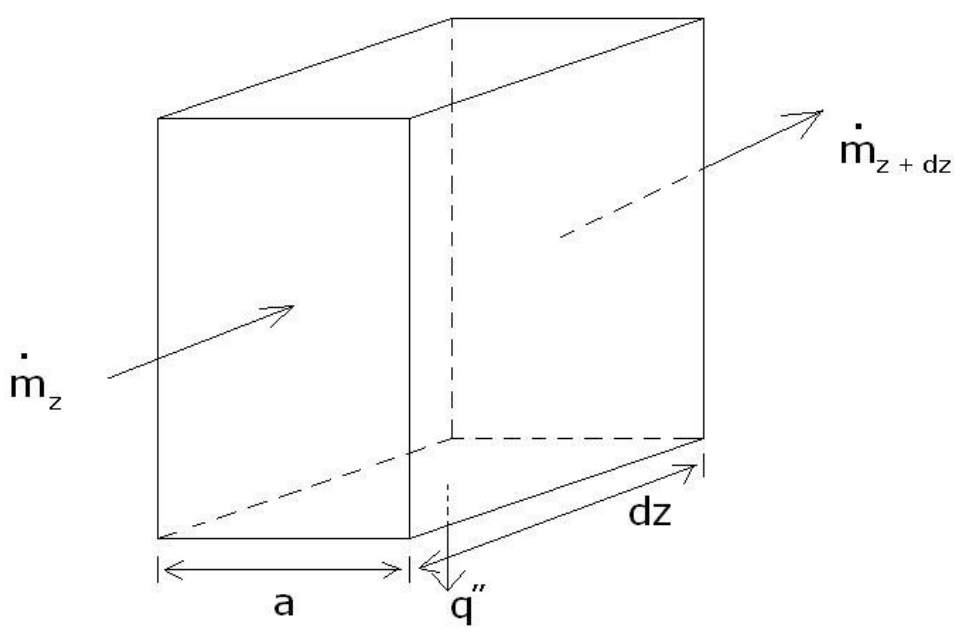

Fig. 7. Differential axial volume element for analyzing condenser channel.

To develop a scaling parameter from this equation, it is necessary to express both $\delta$ and $\mathrm{X}$ in terms of the void fraction, $\alpha$. The parameters $\alpha$ and $\mathrm{X}$ are related by ${ }^{5}$

$$
\left(\mathrm{V}_{1} / \mathrm{V}_{\mathrm{V}}\right)(1-\alpha) / \alpha=\left(\rho_{\mathrm{v}} / \rho_{1}\right)(1-\mathrm{X}) / \mathrm{X}
$$

Furthermore, for a relatively low velocity 1-D flow like that found in most of the condenser channel under a microgravity environment, the slip ratio $\left(\mathrm{V}_{\mathrm{l}} / \mathrm{V}_{\mathrm{v}}\right)$ can be assumed equal to one. Thus, it follows that

and

$$
d X=\left(X^{2} / \alpha^{2}\right)\left(\rho_{1} / \rho_{v}\right) d \alpha,
$$

$$
\left(\mathrm{d} \alpha / \mathrm{dz} \mathrm{z}^{*}\right)\left(\mathrm{X}^{2} / \alpha^{2}\right)=-\left[\mathrm{k}_{\mathrm{l}} \mathrm{a}\left(\mathrm{T}_{\mathrm{sat}}-\mathrm{T}_{\mathrm{w}}\right) \mathrm{L} \rho_{\mathrm{v}}\right] /\left(\mathrm{m}_{\mathrm{flow}} \mathrm{h}_{\mathrm{fg}} \delta \rho_{\mathrm{l}}\right)
$$


Now $X=\left[1+\left(\rho_{\mathrm{l}} / \rho_{\mathrm{v}}\right)(1-\alpha) / \alpha\right]^{-1}$, and for $\rho_{\mathrm{l}}>>\rho_{\mathrm{v}}$ one has $X^{2} / \alpha^{2} \approx\left(\rho_{\mathrm{v}} / \rho_{\mathrm{l}}\right)^{2} /(1-\alpha)^{2}$. If one also assumes a narrow channel gap where $\mathrm{a} \gg \mathrm{b}$, a reasonable approximation would be a linear variation in $\delta$ with $\alpha$ along the condenser channel, so

$$
\delta=(b / 2)(1-\alpha)
$$

As expected, this expression for $\delta$ reduces to $\delta=0$ when $\alpha=1$ and $\delta=\mathrm{b} / 2$ when $\alpha=0$. This relationship between $\delta$ and $\alpha$ relies on the assumption that surface tension leads to an approximately symmetric annular flow in the channel (as seen in Fig. 5), even though heat transfer only occurs on the channel inner surface. Substituting these expressions back into the differential equation shows that

$$
\mathrm{d} \alpha /(1-\alpha)=-2\left\{\left[\mathrm{k}_{1} \mathrm{a}\left(\mathrm{T}_{\mathrm{sat}}-\mathrm{T}_{\mathrm{w}}\right) \mathrm{L} \rho_{\mathrm{l}}\right] /\left(\mathrm{m}_{\mathrm{flow}} \mathrm{h}_{\mathrm{fg}} \rho_{\mathrm{v}} \mathrm{b}\right)\right\} \mathrm{dz}^{*} .
$$

Thus, the normalized scaling parameter, HTP, that will make the solutions for $\alpha\left(\mathrm{z}^{*}\right)$ similar can be defined by

$$
\mathrm{HTP}=\left[\mathrm{k}_{\mathrm{l}} \mathrm{a}\left(\mathrm{T}_{\mathrm{sat}}-\mathrm{T}_{\mathrm{w}}\right) \mathrm{L} \rho_{\mathrm{l}}\right] /\left(\mathrm{m}_{\mathrm{flow}} \mathrm{h}_{\mathrm{fg}} \rho_{\mathrm{v}} \mathrm{b}\right)
$$

Matching the HTP should lead to similar profiles for the void fraction vs normalized axial coordinate along the condenser channels.

\subsection{SCALED PARAMETER VALUES FOR REAL CONDENSER SYSTEM}

The primary normalized quantities for scaling of the condenser design are the inlet Reynolds number, the HTP, the inlet quality, the exit Reynolds number, and the helix pitch ratio. Values for these parameters were evaluated from the condenser design of Ref. 3. To evaluate the Reynolds number for a noncircular cross section like the condenser, it is necessary to define an equivalent hydraulic diameter, $\mathrm{D}_{\mathrm{h}}$, using

$$
\mathrm{D}_{\mathrm{h}}=4 \mathrm{~A}_{\mathrm{c}} / \mathrm{P}_{\mathrm{w}}
$$

in which $\mathrm{A}_{\mathrm{c}}$ is the flow cross-sectional area, and $\mathrm{P}_{\mathrm{w}}$ is the wetted perimeter. Using the terminology already defined for the condenser geometry and assuming there are 12 helical channels, the hydraulic diameter is given by:

$$
D_{h}=\left[\pi\left(D_{\text {outer }}^{2}-D_{\text {in }}^{2}\right)-48 b t\right] /\left[\pi\left(D_{\text {outer }}+D_{\text {in }}\right)+24(b-t)\right],
$$

where $D_{\text {outer }}$ and $D_{\text {in }}$ are the outer and inner annulus diameters, $b=\left(D_{\text {outer }}-D_{\text {in }}\right) / 2$ is the annular gap, and $t=0.01$ in. is the helical fin thickness. For the condenser geometry defined in Table 2, the corresponding hydraulic diameters are 0.2796 in. at the condenser inlet and $9.806 \times 10^{-3} \mathrm{in}$. at the condenser exit. Due to the specified ratio of 12 boiler tubes for 111 condenser tubes, ${ }^{3}$ a condenser tube has only $12 / 111=10.81 \%$ of the mass flow rate found in a boiler tube. Evaluating the primary normalized parameters for the condenser system then yields

- $\mathrm{Re}_{\mathrm{i}}=1113$ (inlet Reynolds number)

- $\mathrm{HTP}=35.44$ (heat transfer parameter)

- $\mathrm{X}_{\mathrm{i}}=0.752$ (inlet quality)

- $\mathrm{X}_{\mathrm{O}}=0.0$ (outlet quality) 
- $\mathrm{Re}_{\mathrm{o}}=419.2$ (outlet Reynolds number)

- $\mathrm{P} / \mathrm{D}=1\left(45^{\circ}\right.$ helix pitch $)$

\subsection{GENERAL EVALUATION PROCESS FOR SCALED CONDENSER PARAMETERS}

For scaling of the condenser design, it is convenient to express the Reynolds number in terms of the condenser mass flow rate and wetted perimeter.

$$
\operatorname{Re}=4 \mathrm{~m}_{\text {flow }} /\left(\mathrm{P}_{\mathrm{w}} \mu\right)
$$

where $P_{w}=\pi\left(D_{\text {outer }}+D_{\text {in }}\right)+24(b-t)$ assuming 12 helical fins with thickness $t=0.01$ in. It is intended to use the scaled boiler tube as a source of vapor to the condenser experiment. However to replicate the actual flow distribution between condenser and boiler tubes, condenser $\mathrm{m}_{\text {flow }}$ will equal only $10.81 \%$ of the output from the scaled boiler design. Because $b=\left(D_{\text {outer }}-D_{\text {in }}\right) / 2$ and the mass flow rate is fixed, matching the Reynolds number allows either $D_{\text {outer }}$ or $D_{\text {in }}$ to be selected independently. To match the general configuration of the actual condenser, $\mathrm{D}_{\text {in }}$ will be held constant over the entire length of the scaled unit, while $\mathrm{D}_{\text {outer }}$ will taper down from inlet to exit. Once the condenser annulus diameters have been determined, it is possible to calculate the dimensions of the individual channels for evaluating the heat transfer parameters.

$$
\begin{gathered}
\mathrm{a}=\pi \mathrm{D}_{\text {in }} / 12-\mathrm{t} . \\
\mathrm{b}=\left(\mathrm{D}_{\text {outer }}-\mathrm{D}_{\text {in }}\right) / 2 .
\end{gathered}
$$

The HTP $=\left[\mathrm{k}_{1}\right.$ a $\left.\left(\mathrm{T}_{\text {sat }}-\mathrm{T}_{\mathrm{w}}\right) \mathrm{L} \rho_{\mathrm{l}}\right] /\left(\mathrm{m}_{\text {flow }} \mathrm{h}_{\mathrm{fg}} \rho_{\mathrm{v}} \mathrm{b}\right)$ is then used to calculate the condensation temperature difference $\left(\mathrm{T}_{\mathrm{sat}}-\mathrm{T}_{\mathrm{w}}\right)$ needed to meet similarity constraints. This temperature difference determines the heat sink temperature necessary for cooling the scaled condenser and the average temperature at which condensate exits the scaled condenser.

The mean fluid temperature for the exiting condensate is given by:

$$
\mathrm{T}_{\mathrm{m}, \text { condensate }}=\left(\mathrm{T}_{\mathrm{sat}}+\mathrm{T}_{\mathrm{w}}\right) / 2 \text {. }
$$

And the heat transfer from the condensing vapor can be found from

$$
\mathrm{q}=\mathrm{m}_{\text {flow }}\left[\mathrm{X}_{\mathrm{i}} \mathrm{h}_{\mathrm{fg}}+\mathrm{c}_{\mathrm{p}}\left(\mathrm{T}_{\mathrm{sat}}-\mathrm{T}_{\mathrm{m}, \text { condensate }}\right)\right] \text {. }
$$

The average heat transfer coefficient for absorption of this heat into the inner tube that carries the ultimate heat sink fluid is then

$$
h_{\text {avg }}=q /\left[\pi D_{\text {in }} L\left(T_{w}-T_{\text {sink coolant }}\right)\right]
$$

Finally, the average heat transfer coefficient can be related to the flow conditions and properties of the heat sink fluid by the Dittus-Boelter correlation: ${ }^{6}$

$$
\mathrm{Nu}=\mathrm{h}_{\mathrm{avg}} \mathrm{D}_{\text {in }} / \mathrm{k}_{\mathrm{l} \text {, sink }}=0.023 \operatorname{Re}_{\text {sink fluid }}{ }^{0.8} \operatorname{Pr}^{0.4}
$$


and the temperature increase of the heat sink fluid while passing through the condenser is given by

$$
T_{o, \text { sink }}-T_{i, \text { sink }}=q /\left(m_{\text {sink flow }} c_{p}\right) .
$$

\subsection{LOW-PRESSURE SCALED CONDENSER SOLUTION}

The low-pressure scaled condenser described below is set up to work with the low-pressure boiler tube design from Sect. 4.3. For this scaled condenser option, an inner annulus diameter of 0.75 in. was selected. Matching the inlet Reynolds number led to an outer annulus diameter of 0.845 in. at the condenser inlet. However, it proved impossible to match the outlet Reynolds number of 419.2 simultaneously. Instead, an exit annular gap of $0.01 \mathrm{in}$. that is similar to the actual condenser geometry was selected. This choice led to an outlet Reynolds number of 38.6, which is somewhat less than 419.2 but even more characteristic of a laminar flow regime. The complete set of design parameters for the low-pressure scaled condenser is summarized in Table 7.

Table 7. Low-pressure scaled condenser design using perfluorohexane

\begin{tabular}{|l|l|}
\hline Inner tube diameter & $19.05 \mathrm{~mm}(0.75 \mathrm{in})$. \\
\hline Outer tube diameter (at inlet) & $21.46 \mathrm{~mm}(0.845 \mathrm{in})$. \\
\hline Outer tube diameter (at outlet) & $19.56 \mathrm{~mm}(0.77 \mathrm{in})$. \\
\hline Number of helical fins & 12 \\
\hline Fin width & $0.254 \mathrm{~mm}(0.01 \mathrm{in})$. \\
\hline Fin helix angle & $45^{\circ}$ \\
\hline Length & $91.44 \mathrm{~cm}(36.0 \mathrm{in})$. \\
\hline Mass flow & $0.54 \mathrm{~g} / \mathrm{s}$ \\
\hline $\mathrm{T}_{\text {sat }}-\mathrm{T}_{\mathrm{W}}$ & $63.5^{\circ} \mathrm{C}$ \\
\hline Heat removal & $52.82 \mathrm{~W}$ \\
\hline Inlet quality & 0.752 \\
\hline Outlet quality & 0.0 \\
\hline Inner wall temperature & $-8.5^{\circ} \mathrm{C}$ \\
\hline Condensation interface temperature & $55.0^{\circ} \mathrm{C}$ \\
\hline Average condensate exit temperature & $23.25^{\circ} \mathrm{C}$ \\
\hline System pressure & $96.05 \mathrm{kPa}(13.9 \mathrm{psi})$ \\
\hline Heat sink fluid & Ethanol \\
\hline Heat sink fluid inlet temperature & $-9.5^{\circ} \mathrm{C}$ \\
\hline Heat sink fluid outlet temperature & $-9.4^{\circ} \mathrm{C}$ \\
\hline Heat sink fluid mass flow & $0.273 \mathrm{~kg} / \mathrm{s}$ \\
\hline Heat sink fluid flow velocity & $1.16 \mathrm{~m} / \mathrm{s}(3.79 \mathrm{ft} / \mathrm{s})$ \\
\hline
\end{tabular}

Of particular interest in the scaled condenser design is the large condensation temperature difference of $\mathrm{T}_{\mathrm{sat}}-\mathrm{T}_{\mathrm{w}}=63.5^{\circ} \mathrm{C}$ across the liquid layer. This value is much greater than the $3.44^{\circ} \mathrm{F}$ found in the real condenser using liquid potassium and is necessary to obtain equivalent heat transfer performance in the scaled system without the high thermal conductivity of liquid metals. Combined with the condensation interface (saturation) temperature of $55.0^{\circ} \mathrm{C}$ near atmospheric pressure, the large condensation temperature difference then requires a heat sink temperature of $-9.5^{\circ} \mathrm{C}$ that is substantially below ambient conditions. Organic liquids like ethanol are needed for reasonable heat transfer performance without excessively high viscosity in this temperature range, but they represent both a fire hazard and a potential toxicity problem. 


\subsection{HIGHER-PRESSURE SCALED CONDENSER SOLUTION}

To avoid the difficulties associated with the low heat sink temperature in the previous condenser design, another set of scaling calculations was completed for a condenser that could be paired with the high-pressure boiler design from Sect. 4.4. A higher condensation temperature of $85^{\circ} \mathrm{C}$ was selected, along with an inner annulus diameter of $0.37 \mathrm{in}$. The inlet Reynolds number similarity condition then required an outer diameter of $0.393 \mathrm{in}$. at the inlet. It again was not possible to match the outlet Reynolds number as well, so a prototypic gap of $0.005 \mathrm{in}$. (which led to an outlet Reynolds number of 43.5) was selected. The calculated design parameters for a condenser system scaled to higher pressure conditions are collected in Table 8.

Table 8. Higher-pressure scaled condenser design using perfluorohexane

\begin{tabular}{|l|l|}
\hline Inner tube diameter & $9.40 \mathrm{~mm}(0.37 \mathrm{in})$. \\
\hline Outer tube diameter (at inlet) & $9.98 \mathrm{~mm}(0.393 \mathrm{in})$. \\
\hline Outer tube diameter (at outlet) & $9.65 \mathrm{~mm}(0.38 \mathrm{in})$. \\
\hline Number of helical fins & 12 \\
\hline Fin width & $0.254 \mathrm{~mm}(0.01 \mathrm{in})$. \\
\hline Fin helix angle & $45^{\circ}$ \\
\hline Length & $45.72 \mathrm{~cm}(18.0 \mathrm{in})$. \\
\hline Mass flow & $0.21 \mathrm{~g} / \mathrm{s}$ \\
\hline $\mathrm{T}_{\text {sat }}-\mathrm{T}_{\mathrm{W}}$ & $64.1^{\circ} \mathrm{C}$ \\
\hline Heat removal & $19.68 \mathrm{~W}$ \\
\hline Inlet quality & 0.752 \\
\hline Outlet quality & 0.0 \\
\hline Inner wall temperature & $20.9^{\circ} \mathrm{C}$ \\
\hline Condensation interface temperature & $85.0^{\circ} \mathrm{C}$ \\
\hline Average condensate exit temperature & $53.0^{\circ} \mathrm{C}$ \\
\hline System pressure & $242.57 \mathrm{kPa}(35.2 \mathrm{psi})$ \\
\hline Heat sink fluid & Water \\
\hline Heat sink fluid inlet temperature & $20.68^{\circ} \mathrm{C}$ \\
\hline Heat sink fluid outlet temperature & $20.72^{\circ} \mathrm{C}$ \\
\hline Heat sink fluid mass flow & $116.5 \mathrm{~g} / \mathrm{s}$ \\
\hline Heat sink fluid flow velocity & $1.682 \mathrm{~m} / \mathrm{s}(5.52 \mathrm{ft} / \mathrm{s})$ \\
\hline
\end{tabular}

As can be seen from Table 8, the higher pressure scaled condenser still has a condensation temperature difference in excess of $60^{\circ} \mathrm{C}$. However, the much higher condensation interface temperature of $85^{\circ} \mathrm{C}$ allows this $\Delta \mathrm{T}$ to be accommodated with a sink fluid inlet temperature of about $20.68^{\circ} \mathrm{C}\left(69.2^{\circ} \mathrm{F}\right)$. Such a design should be compatible with the approximately $70^{\circ} \mathrm{F}$ cooling water and $3 \mathrm{~kW}$ of cooling capacity expected to be available from the moderate temperature loop (MTL) aboard the ISS. ${ }^{7}$ The system mass flow rates and total input power requirements for the higher pressure scaled condenser design are also considerably less than those for the system at low pressure.

\subsection{ADDITIONAL NEAR-SCALE CONDENSER SOLUTIONS AT HIGH PRESSURE}

Three more condenser solutions designed to work with each of the near-scaled boiler designs from Table 5 in Sect. 4.5 are presented in the corresponding three columns of Table 9. These condenser options all feature matching of the inlet Reynolds number, outlet quality, and the heat transfer parameter with the actual potassium Rankine cycle condenser. The scaled outlet Reynolds number of 419.2 could not be matched for any of the designs, with the values achieved ranging from 40.8 to 41.7 . All these condenser designs use water at room temperature as the heat sink fluid. 
Table 9. Near-scaled condenser design solutions using perfluorohexane at high pressure

\begin{tabular}{|l|l|l|l|}
\hline Inner tube diameter & $27.78 \mathrm{~mm}(1.0938 \mathrm{in})$. & $42.07 \mathrm{~mm}(1.6563 \mathrm{in})$. & $56.36 \mathrm{~mm}(2.2188 \mathrm{in})$. \\
\hline Outer tube diameter (at inlet) & $28.50 \mathrm{~mm}(1.122 \mathrm{in})$. & $42.80 \mathrm{~mm}(1.6851 \mathrm{in})$. & $57.04 \mathrm{~mm}(2.2456 \mathrm{in})$. \\
\hline Outer tube diameter (at outlet) & $28.04 \mathrm{~mm}(1.1038 \mathrm{in})$. & $42.32 \mathrm{~mm}(1.6663 \mathrm{in})$. & $56.61 \mathrm{~mm}(2.2288 \mathrm{in})$. \\
\hline Number of helical fins & 12 & 12 & 12 \\
\hline Fin width & $0.254 \mathrm{~mm}(0.01 \mathrm{in})$. & $0.254 \mathrm{~mm}(0.01 \mathrm{in})$. & $0.254 \mathrm{~mm}(0.01 \mathrm{in})$. \\
\hline Fin helix angle & $45^{\circ}$ & $45^{\circ}$ & $45^{\circ}$ \\
\hline Length & $51.21 \mathrm{~cm}(20.16 \mathrm{in})$. & $51.28 \mathrm{~cm}(20.19 \mathrm{in})$. & $47.12 \mathrm{~cm}(18.55 \mathrm{in})$. \\
\hline Mass flow & $0.62 \mathrm{~g} / \mathrm{s}$ & $0.93 \mathrm{~g} / \mathrm{s}$ & $1.23 \mathrm{~g} / \mathrm{s}$ \\
\hline$T_{\text {Sat }}-\mathrm{T}_{\mathrm{W}}$ & $64.1^{\circ} \mathrm{C}$ & $64.1^{\circ} \mathrm{C}$ & $64.1^{\circ} \mathrm{C}$ \\
\hline Heat removal & $57.23 \mathrm{~W}$ & $85.95 \mathrm{~W}$ & $114.36 \mathrm{~W}$ \\
\hline Inlet quality & 0.752 & 0.752 & 0.752 \\
\hline Outlet quality & 0.0 & 0.0 & 0.0 \\
\hline Inner wall temperature & $20.9^{\circ} \mathrm{C}$ & $20.9^{\circ} \mathrm{C}$ & $20.9^{\circ} \mathrm{C}$ \\
\hline Condensation interface temp. & $85.0^{\circ} \mathrm{C}$ & $85.0^{\circ} \mathrm{C}$ & $85.0^{\circ} \mathrm{C}$ \\
\hline Average condensate exit temp. & $53.0^{\circ} \mathrm{C}$ & $53.0^{\circ} \mathrm{C}$ & $53.0^{\circ} \mathrm{C}$ \\
\hline System pressure & $242.57 \mathrm{kPa}(35.2 \mathrm{psi})$ & $242.57 \mathrm{kPa}(35.2 \mathrm{psi})$ & $242.57 \mathrm{kPa}(35.2 \mathrm{psi})$ \\
\hline Heat sink fluid & Water & Water & $\mathrm{Water}$ \\
\hline Heat sink fluid inlet temp. & $20.69^{\circ} \mathrm{C}$ & $19.976^{\circ} \mathrm{C}$ & $19.985^{\circ} \mathrm{C}$ \\
\hline Heat sink fluid outlet temp. & $20.71^{\circ} \mathrm{C}$ & $20.024^{\circ} \mathrm{C}$ & $20.015^{\circ} \mathrm{C}$ \\
\hline Heat sink fluid mass flow & $1.14 \mathrm{~kg} / \mathrm{s}$ & $0.436 \mathrm{~kg} / \mathrm{s}$ & $0.927 \mathrm{~kg} / \mathrm{s}$ \\
\hline Heat sink fluid flow velocity & $1.875 \mathrm{~m} / \mathrm{s}(6.15 \mathrm{ft} / \mathrm{s})$ & $0.314 \mathrm{~m} / \mathrm{s}(1.03 \mathrm{ft} / \mathrm{s})$ & $0.372 \mathrm{~m} / \mathrm{s}(1.22 \mathrm{ft} / \mathrm{s})$ \\
\hline
\end{tabular}

\subsection{ADDITIONAL NEAR-SCALE CONDENSER SOLUTIONS AT LOW PRESSURE}

Another possible way to keep the condenser heat sink fluid near room temperature is to reduce the gap across the condenser annulus compared to the solution from Sect. 5.4. This change thins out the liquid layer accumulating in the condenser channels and improves the heat transfer from the FC-72 vapor. Thus a scaled solution for the condenser using water near $20^{\circ} \mathrm{C}$ as the heat sink fluid becomes practical even with the FC-72 vapor at low pressure. Table 10 presents three such narrow gap condenser solutions at low pressure. The condenser design in the first column of Table 10 is matched with the true-scaled low-pressure boiler from Table 3, while the second and third columns correspond to the respective low-pressure near-scale boiler options in the first and second columns of Table 6 . 
Table 10. Near-scaled condenser design solutions using perfluorohexane at low pressure

\begin{tabular}{|l|l|l|l|}
\hline Inner tube diameter & $26.20 \mathrm{~mm}(1.0313 \mathrm{in})$. & $41.91 \mathrm{~mm}(1.65 \mathrm{in})$. & $55.88 \mathrm{~mm}(2.20 \mathrm{in})$. \\
\hline Outer tube diameter (at inlet) & $26.91 \mathrm{~mm}(1.0595 \mathrm{in})$. & $42.58 \mathrm{~mm}(1.6764 \mathrm{in})$. & $56.62 \mathrm{~mm}(2.2293 \mathrm{in})$. \\
\hline Outer tube diameter (at outlet) & $26.45 \mathrm{~mm}(1.0413 \mathrm{in})$. & $42.16 \mathrm{~mm}(1.66 \mathrm{in})$. & $56.13 \mathrm{~mm}(2.21 \mathrm{in})$. \\
\hline Number of helical fins & 12 & 12 & 12 \\
\hline Fin width & $0.254 \mathrm{~mm}(0.01 \mathrm{in})$. & $0.254 \mathrm{~mm}(0.01 \mathrm{in})$. & $0.254 \mathrm{~mm}(0.01 \mathrm{in})$. \\
\hline Fin helix angle & $45^{\circ}$ & $45^{\circ}$ & $45^{\circ}$ \\
\hline Length & $37.39 \mathrm{~cm}(14.72 \mathrm{in})$. & $34.06 \mathrm{~cm}(13.41 \mathrm{in})$. & $37.67 \mathrm{~cm}(14.83 \mathrm{in})$. \\
\hline Mass flow & $0.54 \mathrm{~g} / \mathrm{s}$ & $0.85 \mathrm{~g} / \mathrm{s}$ & $1.14 \mathrm{~g} / \mathrm{s}$ \\
\hline$T_{\text {sat }}-\mathrm{T}_{\mathrm{W}}$ & $34.0^{\circ} \mathrm{C}$ & $34.0^{\circ} \mathrm{C}$ & $34.0^{\circ} \mathrm{C}$ \\
\hline Heat removal & $44.40 \mathrm{~W}$ & $70.11 \mathrm{~W}$ & $93.43 \mathrm{~W}$ \\
\hline Inlet quality & 0.752 & 0.752 & 0.752 \\
\hline Outlet quality & 0.0 & 0.0 & 0.0 \\
\hline Inner wall temperature & $21.0^{\circ} \mathrm{C}$ & $21.0^{\circ} \mathrm{C}$ & $55.0^{\circ} \mathrm{C}$ \\
\hline Condensation interface temperature & $55.0^{\circ} \mathrm{C}$ & $55.0^{\circ} \mathrm{C}$ & $38.0^{\circ} \mathrm{C}$ \\
\hline Average condensate exit temperature & $38.0^{\circ} \mathrm{C}$ & $38.0^{\circ} \mathrm{C}$ & $96.02 \mathrm{kPa}(13.93 \mathrm{psi})$ \\
\hline System pressure & $96.02 \mathrm{kPa}(13.93 \mathrm{psi})$ & $96.02 \mathrm{kPa}(13.93 \mathrm{psi})$ & Water \\
\hline Heat sink fluid & Water & Water & $19.987^{\circ} \mathrm{C}$ \\
\hline Heat sink fluid inlet temperature & $20.485^{\circ} \mathrm{C}$ & $20.493^{\circ} \mathrm{C}$ & $20.014^{\circ} \mathrm{C}$ \\
\hline Heat sink fluid outlet temperature & $20.515^{\circ} \mathrm{C}$ & $0.828 \mathrm{~kg} / \mathrm{s}$ \\
\hline Heat sink fluid mass flow & $0.367 \mathrm{~kg} / \mathrm{s}$ & $1.168 \mathrm{~kg} / \mathrm{s}$ & $0.338 \mathrm{~m} / \mathrm{s}(1.11 \mathrm{ft} / \mathrm{s})$ \\
\hline Heat sink fluid flow velocity & $0.682 \mathrm{~m} / \mathrm{s}(2.24 \mathrm{ft} / \mathrm{s})$ & $0.848 \mathrm{~m} / \mathrm{s}(2.78 \mathrm{ft} / \mathrm{s})$ & \\
\hline
\end{tabular}




\section{SELECTION OF THE MOST PROMISING SCALED BOILER AND CONDENSER SOLUTIONS}

Table 11 shows a comparison of all the scaled FC-72 boiler solutions developed to date, and Table 12 contains the corresponding scaled condenser data. The two tables are arranged so that the boiler design parameters in each column of Table 11 are paired with the condenser design in the same column of Table 12 immediately below. For comparison purposes, the column in each of these tables labeled "Actual" presents the design details and scaling parameters of the actual Phase II potassium space Rankine cycle boiler and condenser described in Sects. 3, 4.1, and 5.2. Although the specific design details of the actual system are quite different from the scaled solutions in some respects, the matching of the normalized scaling parameters should be noted. It also should be pointed out that Column 1 and Column 6 of Table 11 are identical, because two different scaled condenser solutions (in the corresponding columns of Table 12) were designed to work with that boiler configuration.

The scaling methodology for the boiler design involved matching of the Reynolds and Mach numbers at the boiler exit (as well as $\mathrm{Ja}_{\mathrm{i}}, \mathrm{Ja}_{\mathrm{o}}$, and $\mathrm{P} / \mathrm{D}$ ) to those in the actual potassium Rankine cycle, while the condenser scaling involved matching the inlet Reynolds number, the system heat transfer parameter, $X_{i}, X_{0}$, and the condenser fin helix angles. The exit Reynolds number, $\operatorname{Re}_{\mathrm{O}}$, could not be matched exactly for any of the condenser solutions. The solutions in the first two columns of both tables satisfied all these criteria except $\mathrm{Re}_{\mathrm{o}}$. Other design requirements included a power input to the scaled boiler of $<1 \mathrm{~kW}$ and a heat sink temperature of approximately $20^{\circ} \mathrm{C}$ in the scaled condenser to make the experiment compatible with the Fluids Integrated Rack (FIR) facilities expected to be available aboard the ISS. ${ }^{7}$ Only the higher-pressure solution in Column 2 of Tables 11 and 12 could meet the restriction on heat sink temperature and simultaneously satisfy all scaling criteria.

Although the Column 2 solution satisfied all scaling criteria, there were serious concerns whether the boiler tube diameter of only 0.086 in. $(2.18 \mathrm{~mm})$ would be large enough for effective observation of boiling phenomena or to prevent unrealistic surface tension effects. Thus several additional scaling solutions for the boiler and condenser were developed in Sects. 4.5-4.6 and 5.6-5.7. The results in Columns 3-5 of Tables 11 and 12 were calculated at the same high system pressure conditions as Column 2 (to maintain the condenser heat sink near $20^{\circ} \mathrm{C}$ ) with the boiler tube diameter increased to 0.25 in., 0.375 in., or $0.5 \mathrm{in}$. This increase in the tube diameter made it impossible to continue matching both the exit Reynolds and Mach numbers of the actual Rankine cycle, so the Mach number was allowed to decline accordingly as seen in Table 11. Although this situation is a departure from true experimental similitude, it is thought that for Mach numbers less than 0.3 flow compressibility effects are not particularly significant and the error introduced will be small. Also, even incomplete similarity in an experiment can still yield valuable insight into the actual system behavior. ${ }^{1}$

The remaining entries in Tables 11 and 12 (Columns 6-8) reflect a different approach to a scaled solution with a more acceptable boiler tube diameter. It was recognized that by reducing the gap between $D_{\text {in }}$ and $D_{\text {outer }}$ of the condenser annulus, the aspect ratio $a / b$ is increased and more surface area is available for heat transfer across the accumulated liquid layer in the condenser channels. This change reduces the $\mathrm{T}_{\mathrm{sat}}-\mathrm{T}_{\mathrm{w}}$ necessary for adequate heat transfer from the vapor so that a low-pressure scaled solution for the condenser with the heat sink temperature maintained near $20^{\circ} \mathrm{C}$ could be achieved. Column 6 is a fully scaled low-pressure boiler and condenser solution (with a boiler tube diameter of 0.239 in.). Columns 7 and 8 increase the boiler tube diameter to 0.375 in. and 0.5 in., respectively. Although these larger diameter solutions involve some reduction in the Mach number compared to its true scaling value of 0.152 , the deviation is much less pronounced than seen when enlarging the boiler tube at higher pressure. 


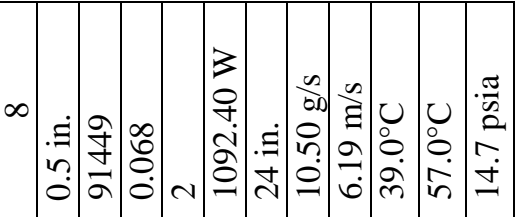

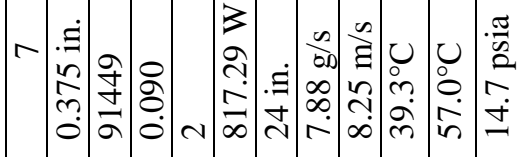

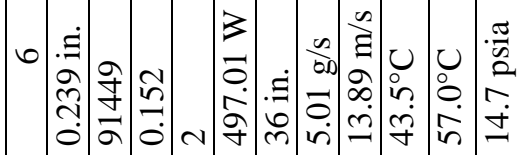

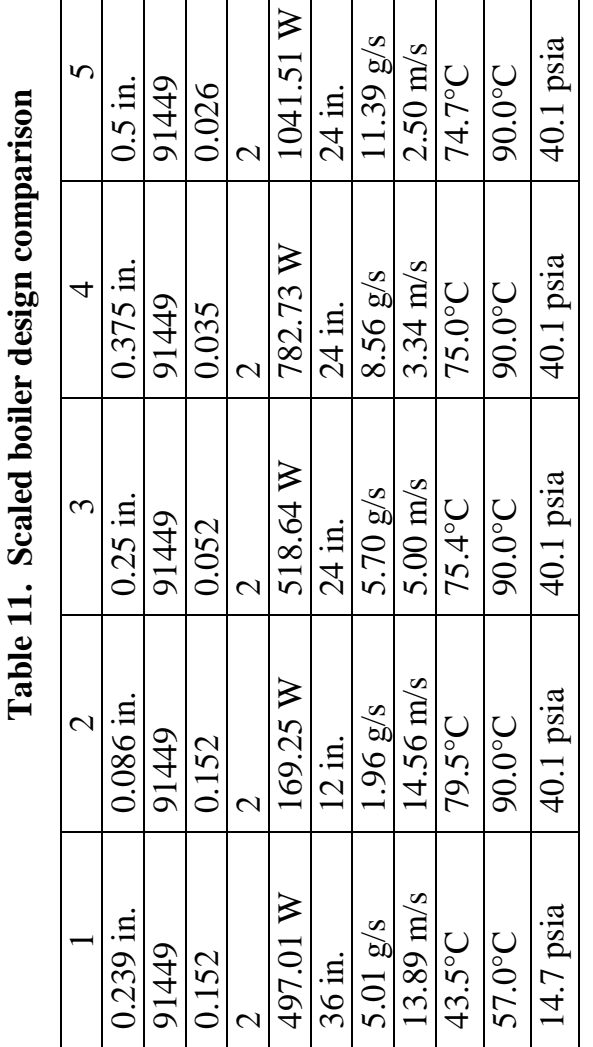

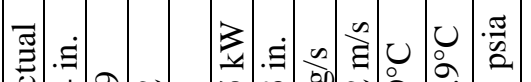

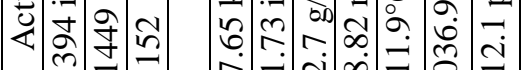
ठำ

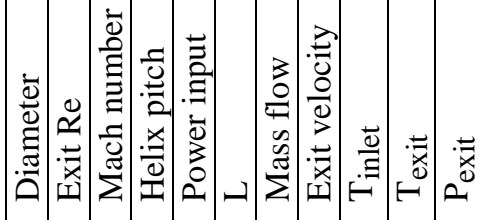

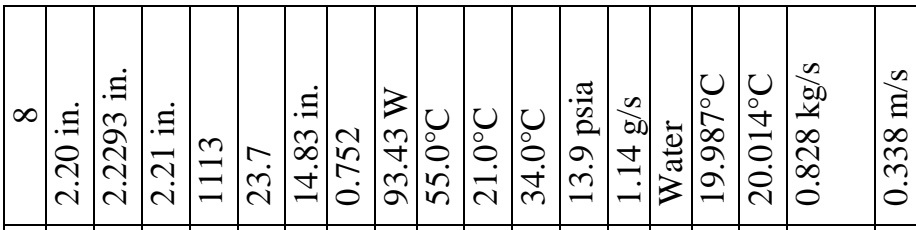

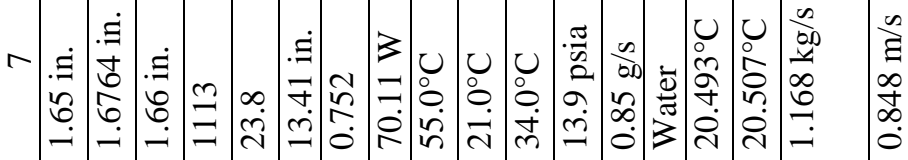

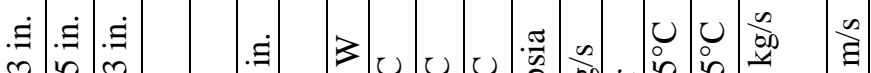

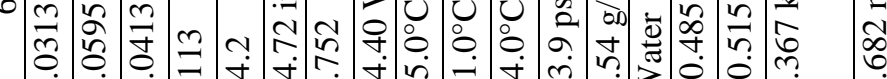

-

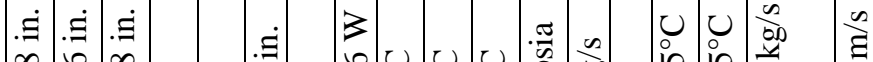

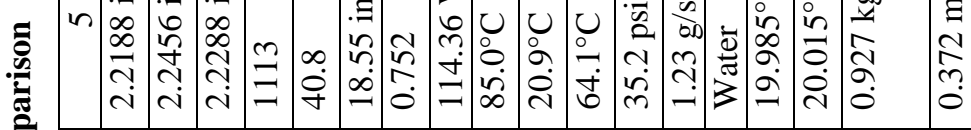

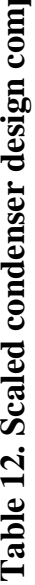

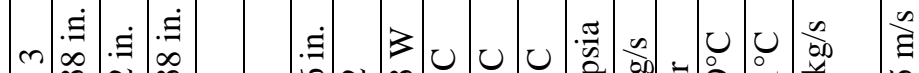

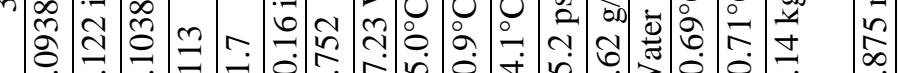

-

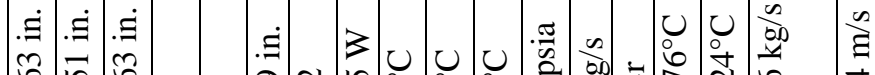

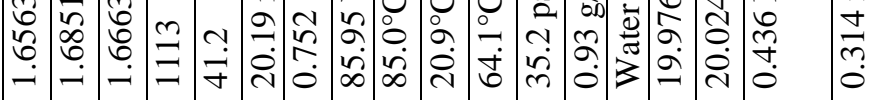

$+$

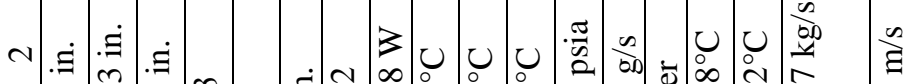

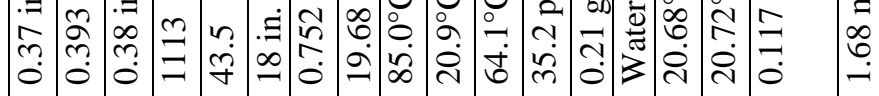

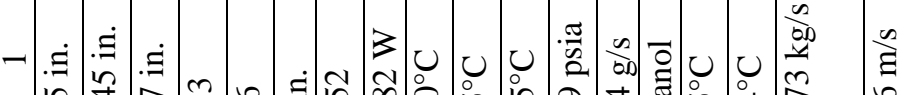

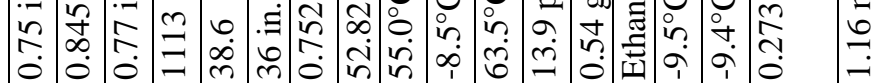

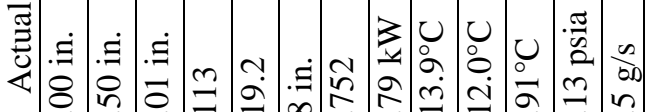

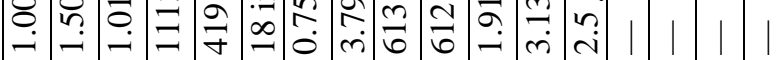

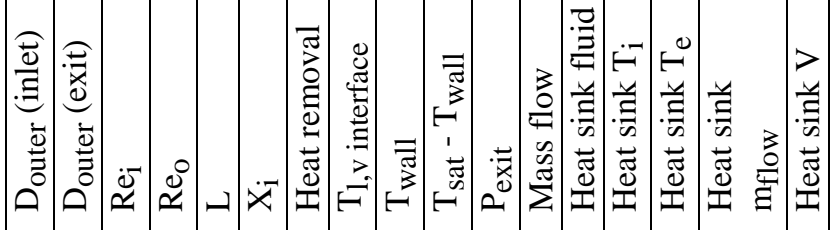


Like most design problems, selection of the most promising preconceptual design from Tables 11 and 12 involves multiple compromises. The low-pressure solutions with reduced condenser gaps appear to provide the closest scaling matches possible with reasonable boiler tube sizes. Unfortunately, the 0.5 -in. diameter solution (Column 8) exceeds the $1-\mathrm{kW}$ allowable boiler power requirement by almost $10 \%$. Therefore, the best choice available seems to be between the solutions in Columns 6 and 7 of the tables. The main difference between these two solutions is that Column 6 allows a full scaling match of the boiler exit Mach number, while Column 7 offers the superior visualization and instrumentation capabilities of a 0.375 -in. tube diameter at slightly reduced Mach number (0.09 instead of 0.152). With all these factors taken into account, it was felt that Column 7 was the best possible compromise to obtain adequate scaling results as well as a reasonably convenient experiment. Hence all the subsequent preconceptual boiler and condenser design development was based on the Column 7 scaling solution. 


\section{PRECONCEPTUAL SCALED BOILER DESIGN}

The thermal-hydraulic parameters of the selected preconceptual scaled boiler design are summarized in Table 13, and a dimensioned fabrication drawing is shown in Fig. 8. Heat input to the scaled boiler is provided by water at $95^{\circ} \mathrm{C}$ flowing through a 1 -in. square shell surrounding the boiler tube. According to calculations with the Dittus-Boelter correlation, ${ }^{6}$ a mass flow rate of about $0.173 \mathrm{~kg} / \mathrm{s}$ (which corresponds to a water flow velocity of $0.329 \mathrm{~m} / \mathrm{s}$ in the shell) would need to be maintained for adequate heat transfer to the perfluorohexane (FC-72), including the effect of the temperature drop across the boiler tube wall. The temperature change in the $95^{\circ} \mathrm{C}$ water due to heat loss to the FC-72 is only about $1.1^{\circ} \mathrm{C}$ during passage through the shell. Pressure in the shell can be atmospheric or even slightly subatmospheric and still maintain the water as single-phase liquid at $95^{\circ} \mathrm{C}$.

The heating shell surrounding the scaled boiler tube will be fabricated from clear Plexiglas plastic for unobstructed viewing of the boiling phenomena as well as thermal insulation of the hot fluid from the environment. A square configuration was selected for the surrounding shell to minimize optical distortion during the observations. The scaled boiler tube itself needs to be made from borosilicate (Pyrex) glass because transparent plastics like Plexiglas have insufficient thermal conductivity for proper heat conduction through the tube walls. The helical boiler tube insert will be fabricated from a thin aluminum strip, which has both good ductility for easy twisting into a helix shape and high thermal conductivity to allow radial diffusion of heat from the tube walls to the center of the tape. Figures 9-11 are pictorial illustrations of the scaled FC-72 boiler unit. Figure 9 shows an overall view with part of the shell cut away to reveal the boiler tube and insert, while Fig. 10 is a closer view of the cut-away area. Figure 11 is an extreme close-up focusing on details of the boiler tube and helical insert for the preconceptual scaled boiler design.

Table 13. Thermal-hydraulic parameters for the preconceptual scaled perfluorohexane boiler experiment design

\begin{tabular}{|l|l|}
\hline Tube inner diameter & $9.53 \mathrm{~mm}(0.375 \mathrm{in})$. \\
\hline Tube length & $60.96 \mathrm{~cm}(24.0 \mathrm{in})$. \\
\hline Helix pitch ratio & $\mathrm{P} / \mathrm{D}=2$ \\
\hline Tube mass flow & $7.88 \mathrm{~g} / \mathrm{s}$ \\
\hline Power input & $817.29 \mathrm{~W}$ \\
\hline Inlet temperature & $39.3^{\circ} \mathrm{C}$ \\
\hline Inlet pressure & $103.22 \mathrm{kPa}(14.975 \mathrm{psi})$ \\
\hline Outlet temperature & $57.0^{\circ} \mathrm{C}$ \\
\hline Outlet pressure & $101.30 \mathrm{kPa}(14.7 \mathrm{psi})$ \\
\hline Flow outlet velocity & $8.25 \mathrm{~m} / \mathrm{s}(27.07 \mathrm{ft} / \mathrm{s})$ \\
\hline Tube pressure drop & $1.90 \mathrm{kPa}(0.275 \mathrm{psi})$ \\
\hline Outlet quality & 1.00 \\
\hline
\end{tabular}




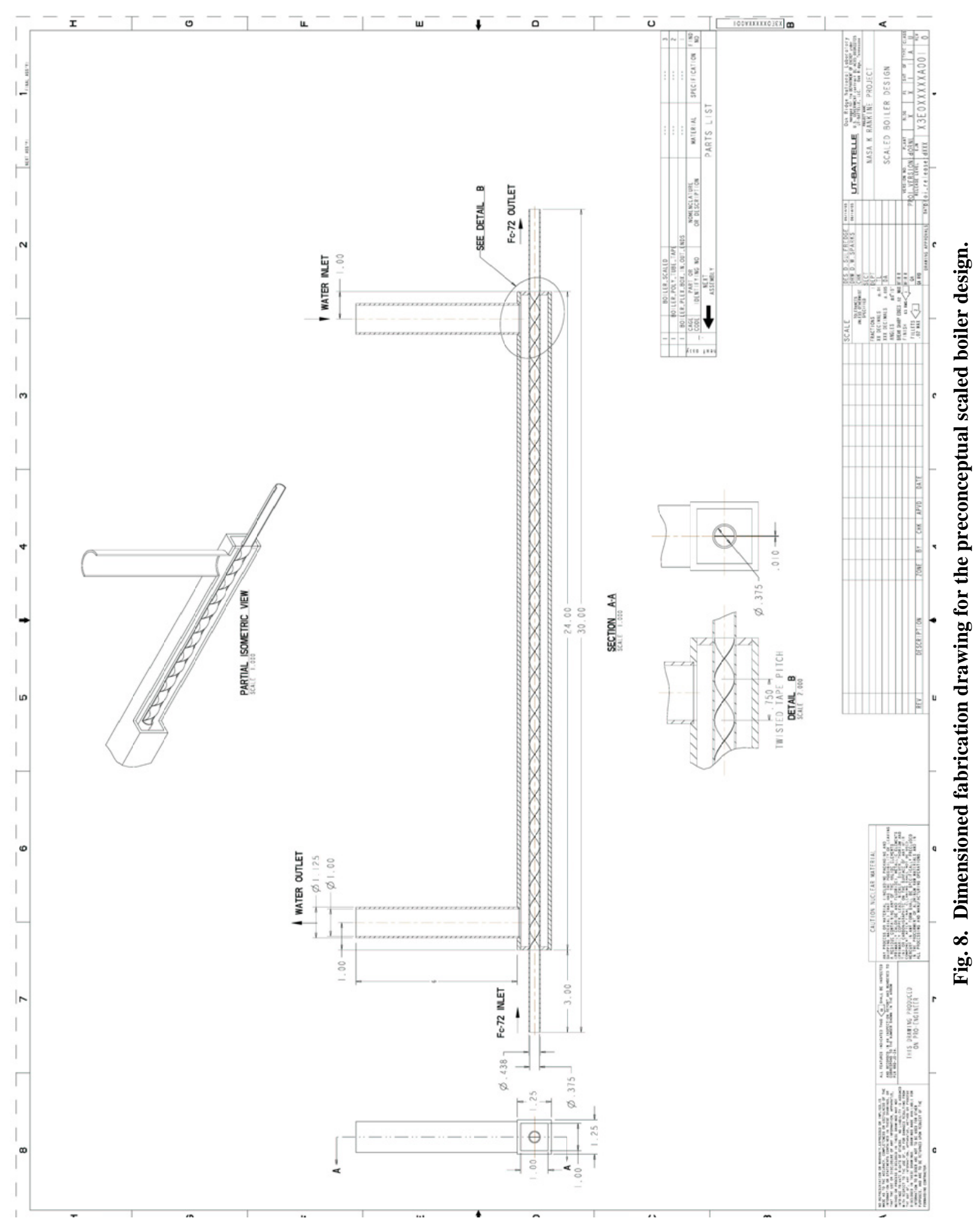




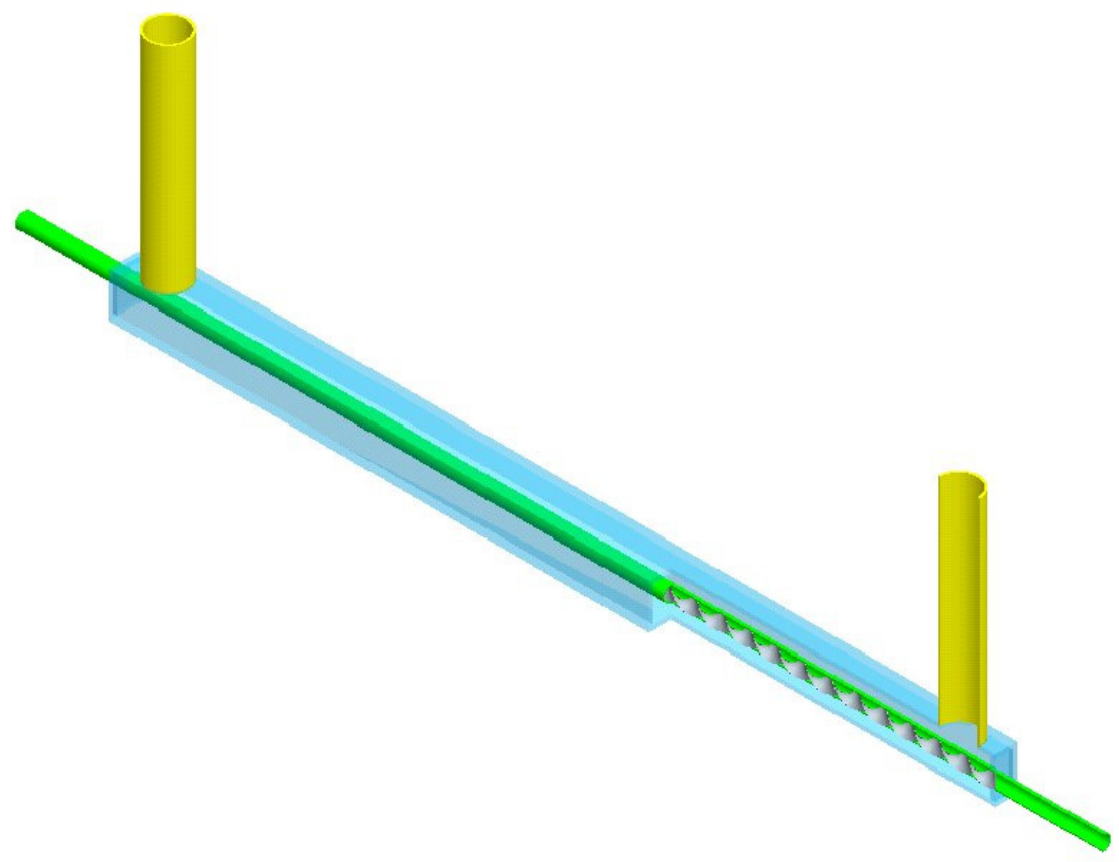

Fig. 9. Overall pictorial drawing of the preconceptual scaled boiler design.

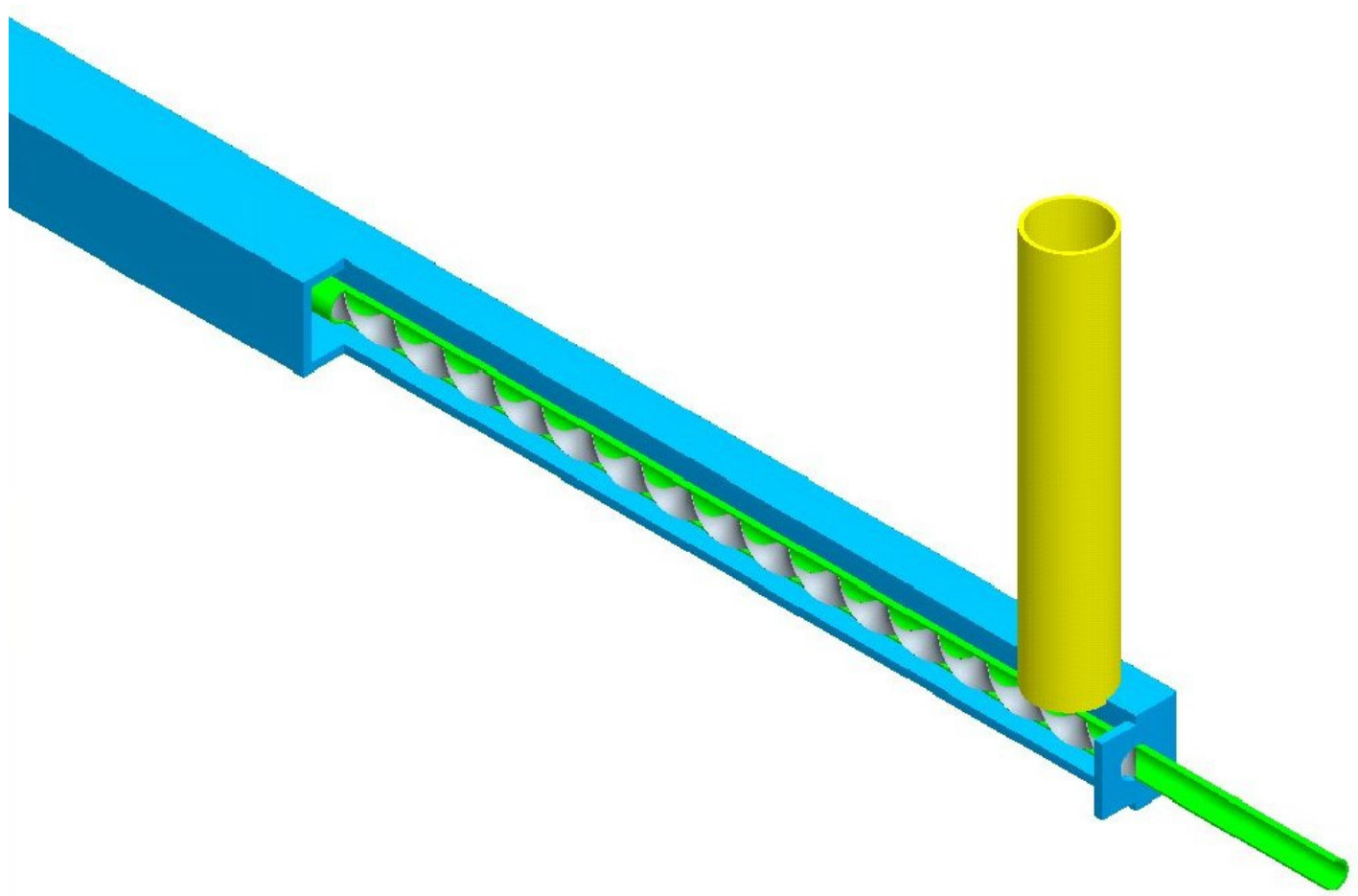

Fig. 10. More detailed pictorial view of the scaled boiler design showing the heating shell end cap in place. 


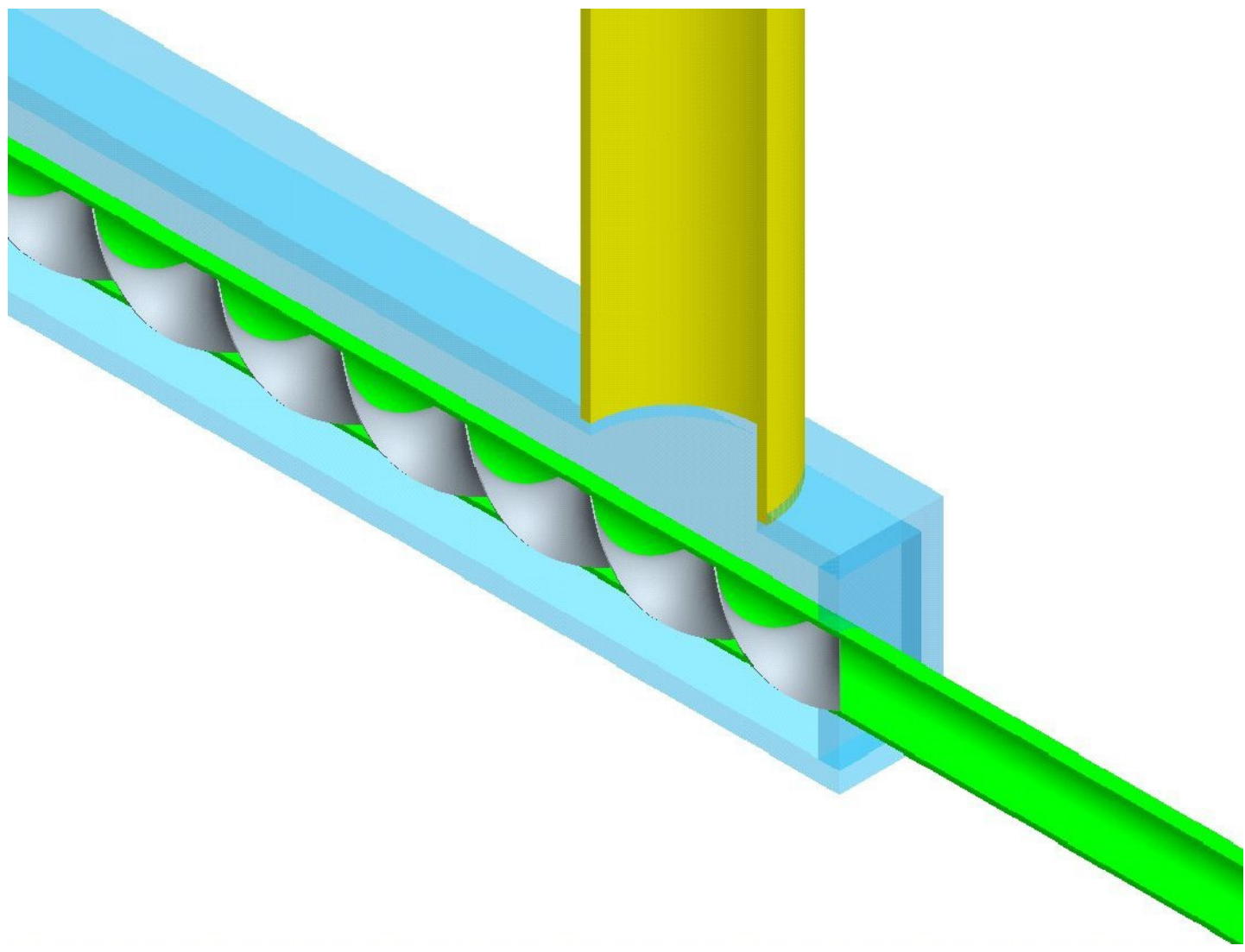

Fig. 11. Close-up pictorial view of the scaled boiler tube and helical insert. 


\section{PRECONCEPTUAL SCALED CONDENSER DESIGN}

Table 14 includes thermal-hydraulic parameters selected for the preconceptual scaled condenser design, and Fig. 12 shows the dimensioned fabrication drawing for the scaled condenser. The inner wall of the condenser annulus, as well as the helical fins attached to it, will be made of copper to promote efficient heat transfer and minimal temperature drop. The external annulus wall surrounding the copper pipe will be constructed from clear Plexiglas to allow observation of the perfluorohexane (FC-72) flow in the condenser channels. To improve the swirl flow characteristics and minimize pressure drop across the condenser, the FC-72 inlet manifold will bring the vapor flow in tangentially to the condenser annulus, and the FC-72 outlet manifold will draw the liquid off tangentially from the opposite side of the annulus at the far end of the condenser. Low-conductivity plastic will be used for the cooling water pipe to provide thermal insulation of the heat sink water flow everywhere except in the finned copper segment.

Figures 13-19 are pictorial illustrations of the scaled FC-72 condenser unit and its components. Figure 13 shows the overall condenser assembly, while Fig. 14 presents a cutaway drawing from the same perspective, and Fig. 15 gives a close-up of the FC-72 inlet end. Crosssections through the FC-72 inlet and exit manifolds are presented in Figs. 16 and 17. Figure 18 is an illustration of the copper pipe that makes up the inner wall of the condenser annulus, showing the 12 helical fins spaced around its circumference and how the diameter is swaged down to connect to the thicker plastic pipes at each end of the condenser. A detailed cross-section through the copper-plastic joint at the FC-72 exit manifold can be seen in Fig. 19.

Table 14. Thermal-hydraulic parameters for the preconceptual scaled perfluorohexane condenser experiment design

\begin{tabular}{|l|l|}
\hline Inner tube diameter & $41.91 \mathrm{~mm}(1.65 \mathrm{in})$. \\
\hline Outer tube diameter (at inlet) & $42.58 \mathrm{~mm}(1.6764 \mathrm{in})$. \\
\hline Outer tube diameter (at outlet) & $42.16 \mathrm{~mm}(1.66 \mathrm{in})$. \\
\hline Number of helical fins & 12 \\
\hline Fin width & $0.254 \mathrm{~mm}(0.01 \mathrm{in})$. \\
\hline Fin helix angle & $45^{\circ}$ \\
\hline Length & $34.06 \mathrm{~cm}(13.41 \mathrm{in})$. \\
\hline Mass flow & $0.85 \mathrm{~g} / \mathrm{s}$ \\
\hline $\mathrm{T}_{\text {sat }}-\mathrm{T}_{\mathrm{W}}$ & $34.0^{\circ} \mathrm{C}$ \\
\hline Heat removal & $70.11 \mathrm{~W}$ \\
\hline Inlet quality & 0.752 \\
\hline Outlet quality & 0.0 \\
\hline Inner wall temperature & $21.0^{\circ} \mathrm{C}$ \\
\hline Condensation interface temperature & $55.0^{\circ} \mathrm{C}$ \\
\hline Average condensate exit temperature & $38.0^{\circ} \mathrm{C}$ \\
\hline System pressure & $96.02 \mathrm{kPa}(13.93 \mathrm{psi})$ \\
\hline Heat sink fluid & $\mathrm{Water}$ \\
\hline Heat sink fluid inlet temperature & $20.43^{\circ} \mathrm{C}$ \\
\hline Heat sink fluid outlet temperature & $20.57^{\circ} \mathrm{C}$ \\
\hline Heat sink fluid mass flow & $1.168 \mathrm{~kg} / \mathrm{s}$ \\
\hline Heat sink fluid flow velocity & $0.848 \mathrm{~m} / \mathrm{s}(2.78 \mathrm{ft} / \mathrm{s})$ \\
\hline
\end{tabular}




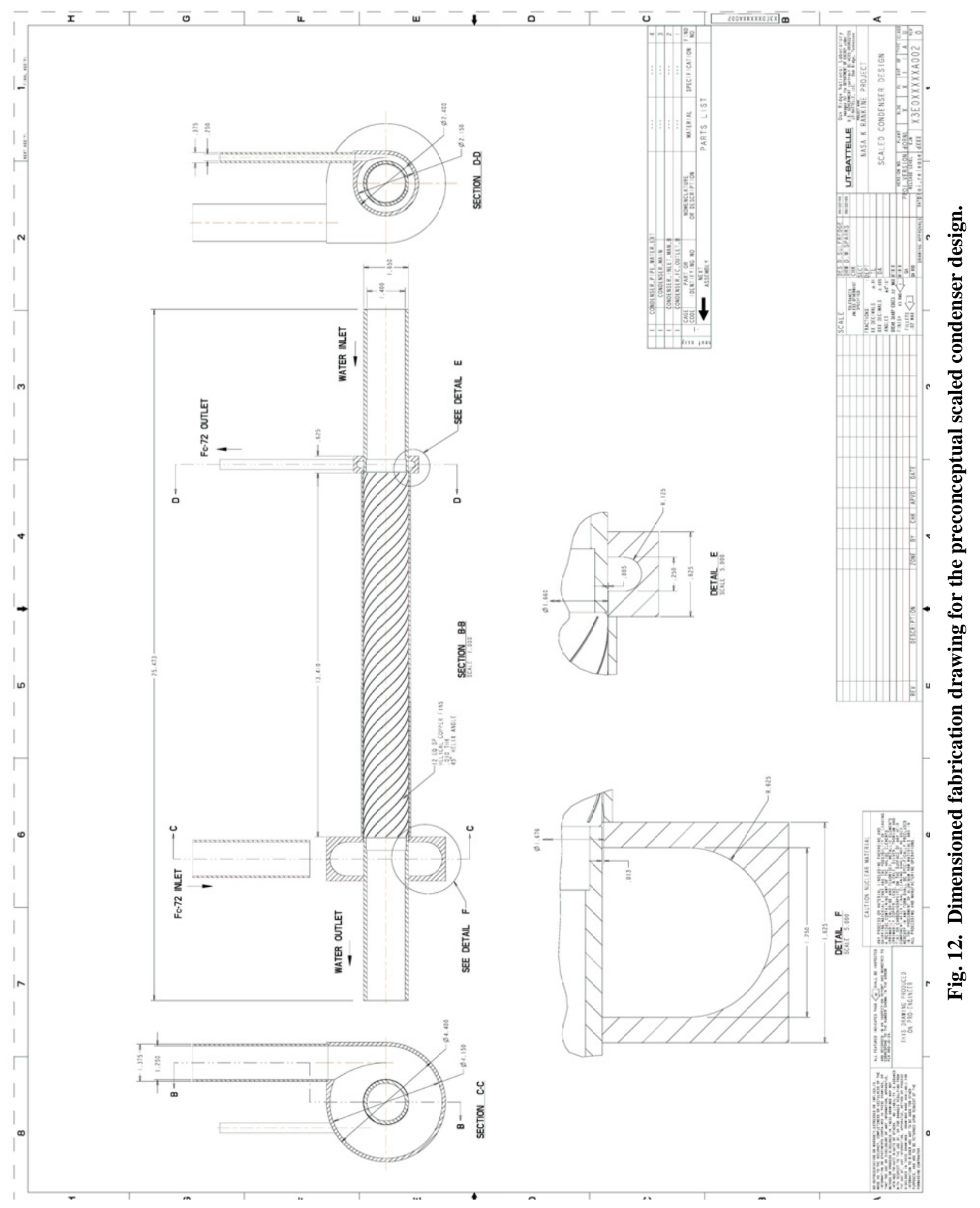




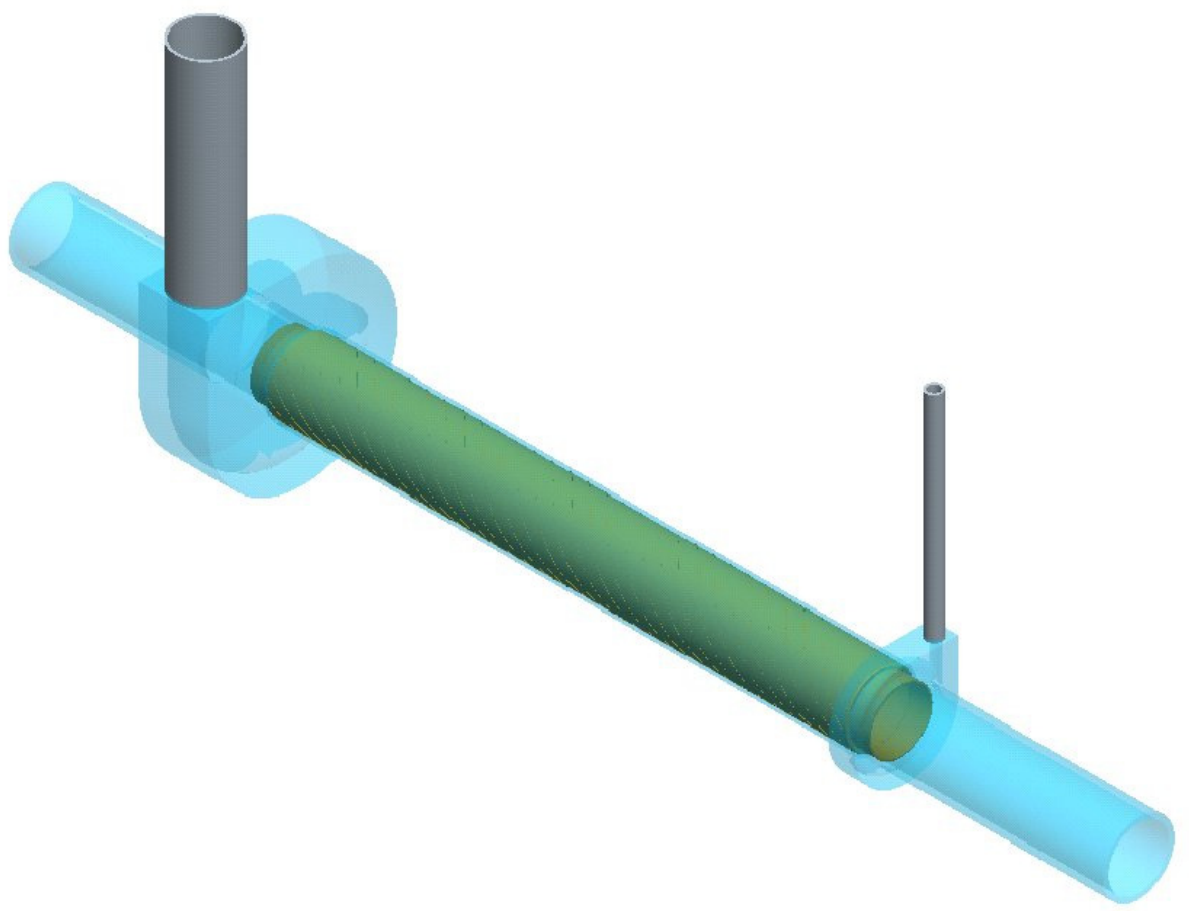

Fig. 13. Overall pictorial drawing of the preconceptual scaled condenser design.

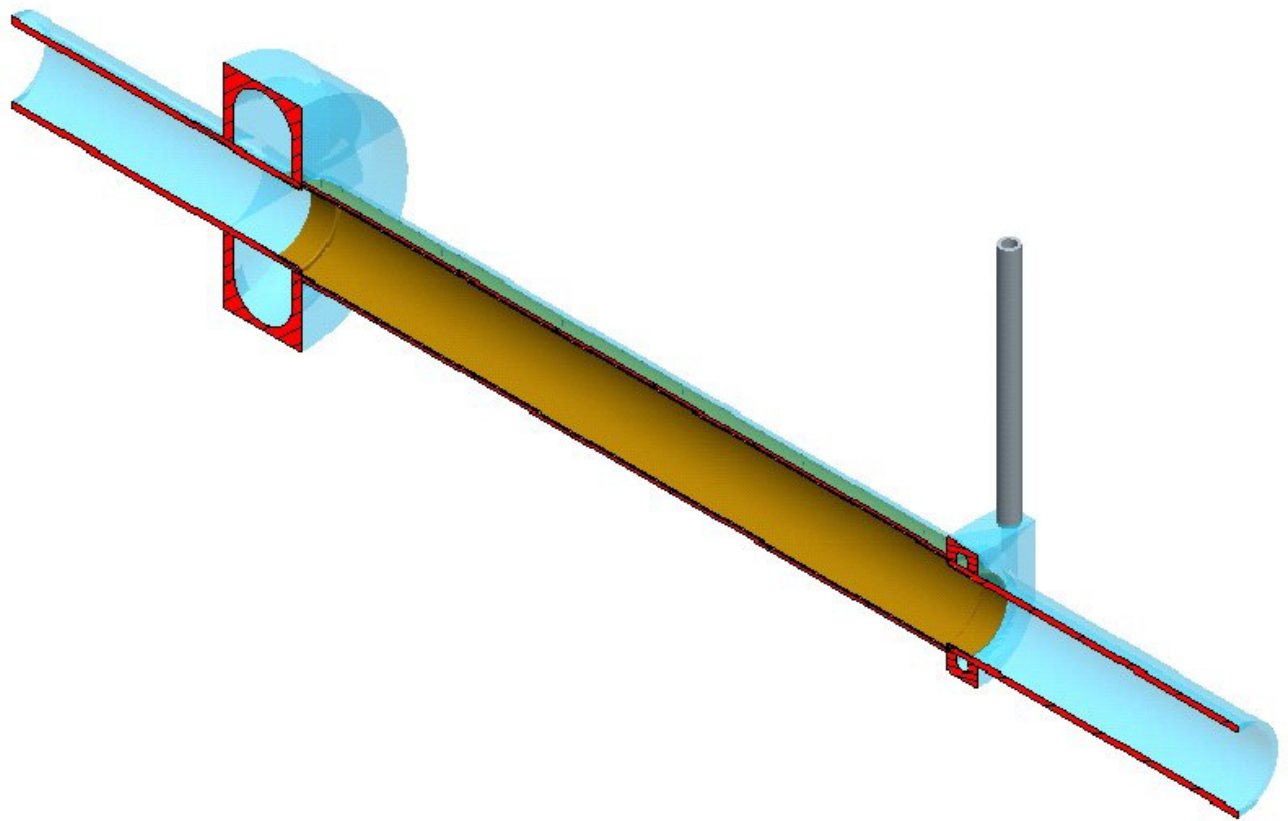

Fig. 14. Overall pictorial cutaway view of the scaled condenser. 


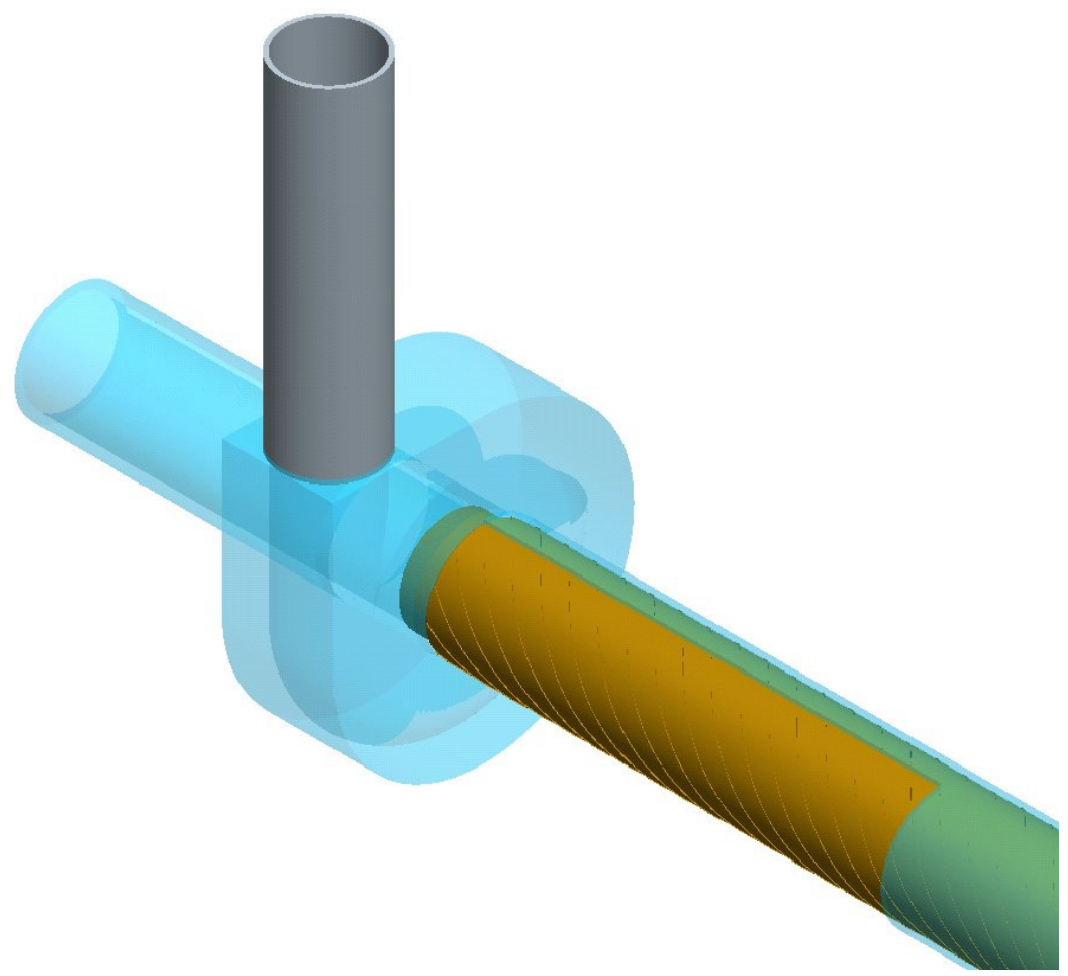

Fig. 15. Pictorial view of the scaled condenser assembly at the perfluorohexane vapor inlet end.

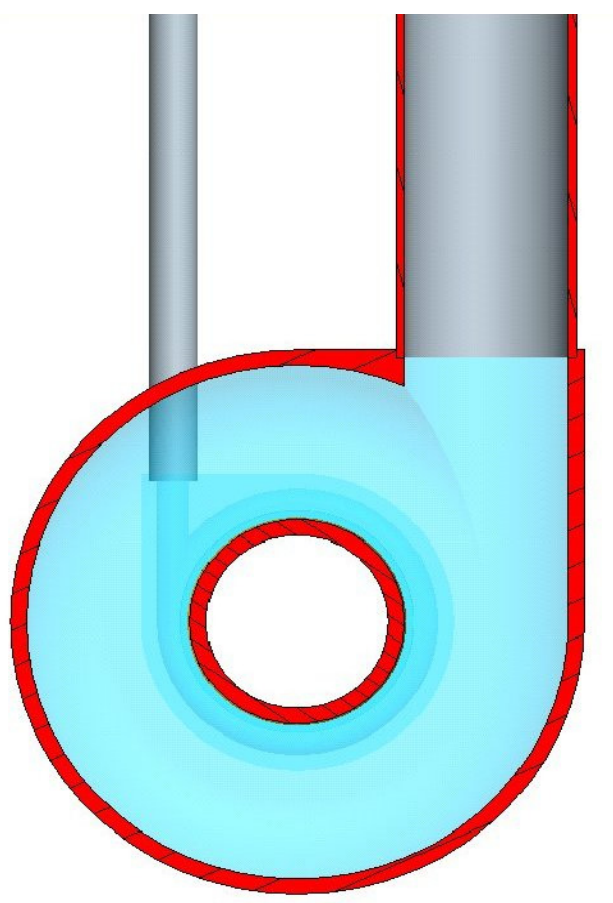

Fig. 16. Cross-section pictorial view through the manifold at the perfluorohexane vapor inlet end of the scaled condenser. 


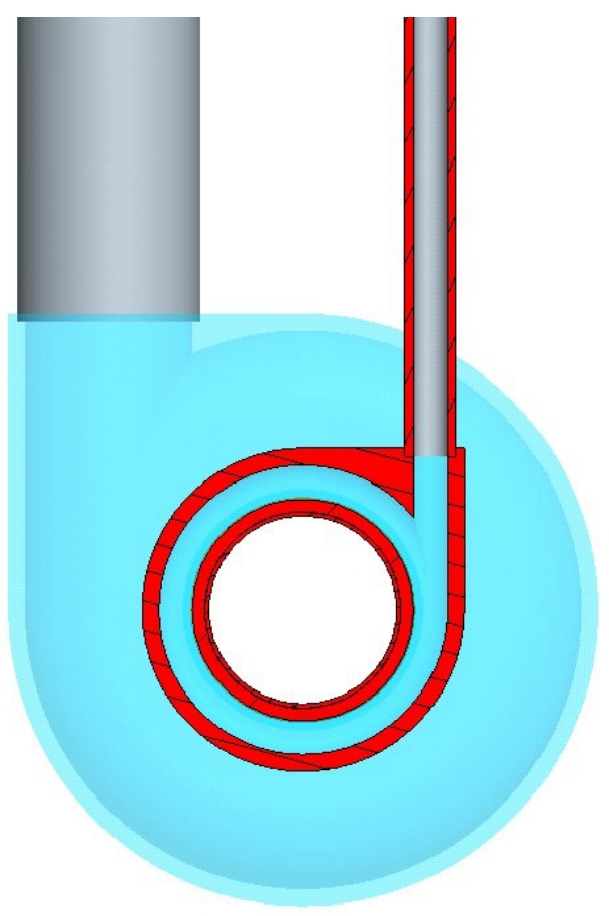

Fig. 17. Cross-section pictorial view through the manifold at the perfluorohexane liquid outlet end of the scaled condenser.

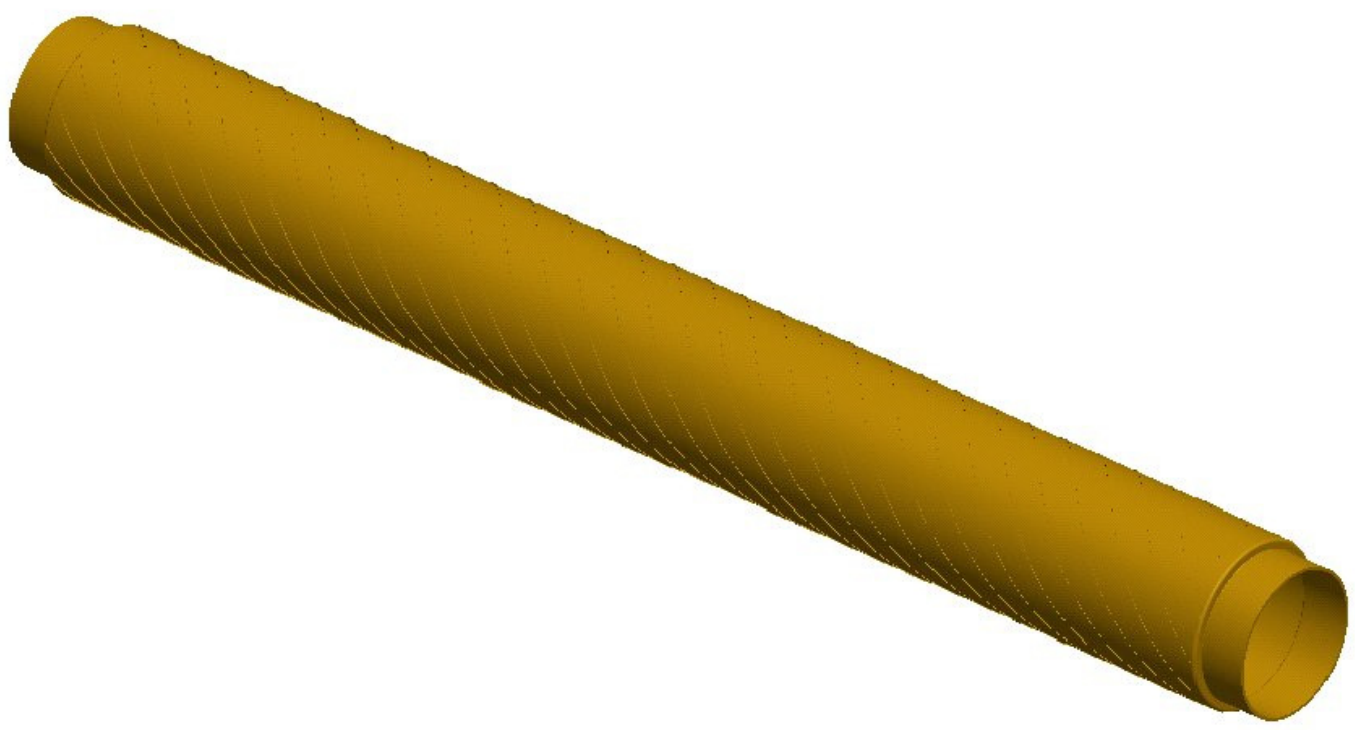

Fig. 18. Pictorial illustration of the copper pipe inner condenser assembly with its helical fins. 


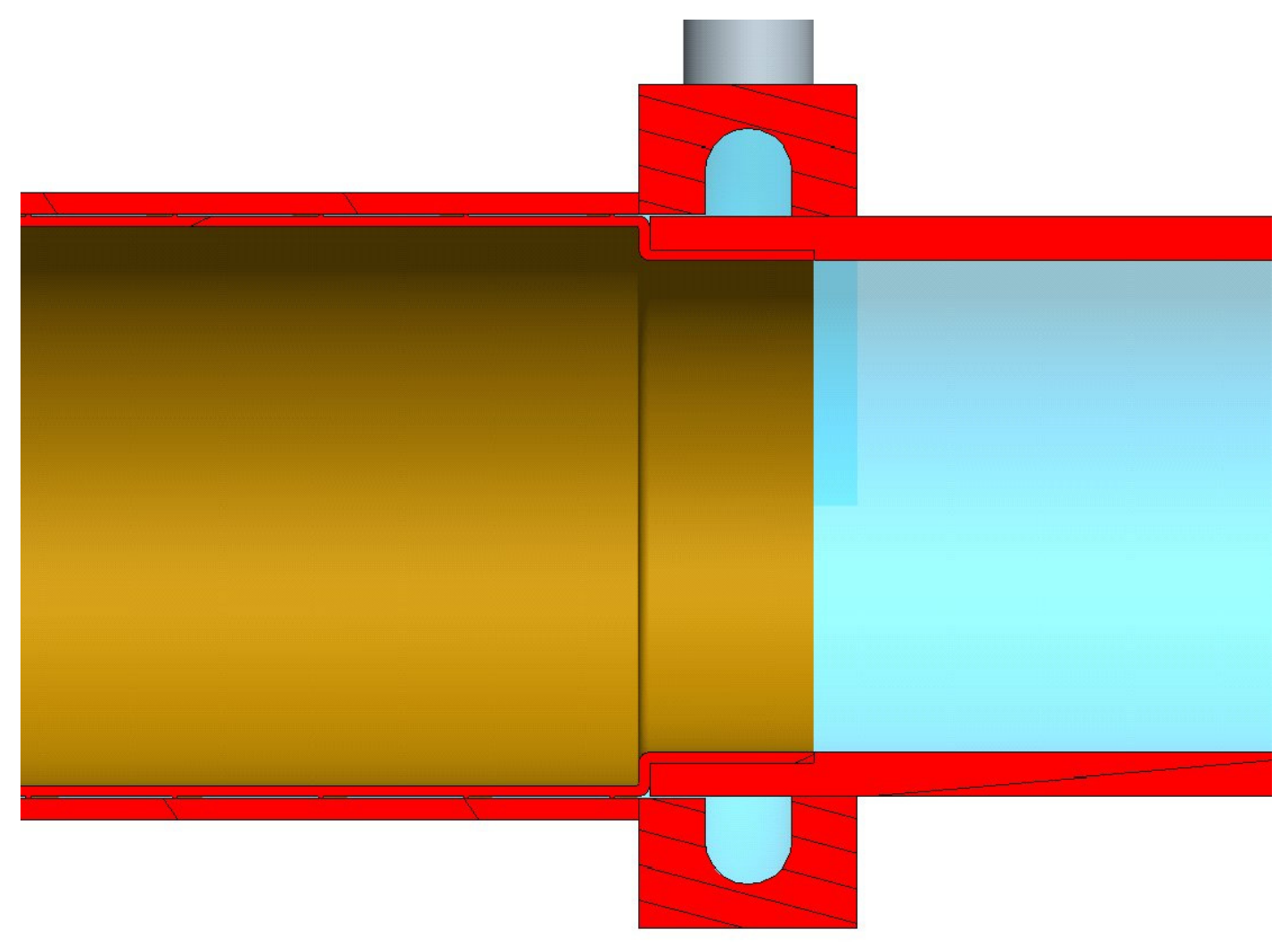

Fig. 19. Illustration of the joint between the copper inner condenser pipe and the insulated plastic extension at the perfluorohexane liquid exit manifold. 


\section{DESCRIPTION OF SCALED PERFLUOROHEXANE LOOP AS AN INTEGRATED UNIT}

Two main additional elements are needed to combine the scaled boiler and condenser so they can work together in a single experimental loop. First, the perfluorohexane vapor flow of $7.88 \mathrm{~g} / \mathrm{s}$ emerging from the boiler tube must be split into two streams so that only $0.85 \mathrm{~g} / \mathrm{s}$ (or $10.81 \%$ of the flow) is delivered to the scaled condenser. This division should be conducted while the flow is entirely single-phase vapor to avoid problems with equal division of multiple phases at a junction. The remaining $7.03 \mathrm{~g} / \mathrm{s}$ of vapor flow needs to be diverted to another (main) condenser to be condensed and prepared for another cycle. Design details of the main loop condenser do not need to meet any particular scaling requirements and can be adjusted for compatibility with the heat sink/space requirements available.

The second consideration is that the $0.85-\mathrm{g} / \mathrm{s}$ flow stream headed for the scaled condenser must be expanded and cooled to obtain a scaled condenser inlet quality of $X=0.752$. This process can be achieved by expanding the vapor flow across an orifice and then passing it through an auxiliary cooler. The auxiliary cooler also does not have to meet any particular scaling requirements other than removing a specified heat load from the flow.

\subsection{SIZING OF LOOP MAIN CONDENSER}

The main condenser needs to be sized so that the liquid stream returned to the boiler inlet has the expected bulk temperature $\left(39.3^{\circ} \mathrm{C}\right)$. Because the average condensate temperature of $38.0^{\circ} \mathrm{C}$ leaving the scaled condenser is somewhat lower than this, the target temperature for the $7.03-\mathrm{g} / \mathrm{s}$ flow stream is actually slightly greater than $39.3^{\circ} \mathrm{C}$ so that the merged streams have the proper temperature. From an energy balance on the two streams:

$$
(7.03 \mathrm{~g} / \mathrm{s})(1071.70 \mathrm{~J} / \mathrm{kg} \mathrm{K})\left(\mathrm{T}_{\text {target }}-39.3^{\circ} \mathrm{C}\right)=(0.85 \mathrm{~g} / \mathrm{s})(1070.70 \mathrm{~J} / \mathrm{kgK})\left(39.3^{\circ} \mathrm{C}-38.0^{\circ} \mathrm{C}\right),
$$

and it follows that the target temperature for the $7.03-\mathrm{g} / \mathrm{s}$ stream is $39.46^{\circ} \mathrm{C}$.

The heat load on the main condenser is then given by

$$
\mathrm{q}_{\text {main }}=(7.03 \mathrm{~g} / \mathrm{s})\left[\mathrm{h}_{\mathrm{fg}}+\mathrm{c}_{\mathrm{p}}\left(57^{\circ} \mathrm{C}-39.46^{\circ} \mathrm{C}\right)\right]=727.73 \mathrm{~W} \text {. }
$$

\subsection{SIZING OF THE LOOP AUXILIARY COOLER AND ORIFICE PRESSURE DROP}

Because the scaled condenser needs to input a two-phase perfluorohexane mixture with quality 0.752 at $55^{\circ} \mathrm{C}$, an orifice must be used to reduce the boiler tube exit pressure of $14.7 \mathrm{psi}$ $(101.3 \mathrm{kPa})$ to $\mathrm{P}_{\mathrm{sat}}\left(55^{\circ} \mathrm{C}\right)=13.93 \mathrm{psi}(96.05 \mathrm{kPa})$. This expansion of the flow must be accompanied by an auxiliary cooler to bring $\mathrm{X}$ down to 0.752 . From an energy balance on the auxiliary cooling process:

$$
\mathrm{q}_{\mathrm{aux}}=(0.85 \mathrm{~g} / \mathrm{s})\left\{0.752 \mathrm{~h}_{\mathrm{fg}, 13.93 \mathrm{psi}}-\left[\mathrm{h}_{\mathrm{fg}, 14.7 \mathrm{psi}}+\mathrm{c}_{\mathrm{p}}\left(57^{\circ} \mathrm{C}-55^{\circ} \mathrm{C}\right)\right]\right\}=19.43 \mathrm{~W} .
$$

\subsection{OVERALL SCHEMATIC OF THE SCALED PERFLUOROHEXANE LOOP}

A schematic diagram summarizing all the thermal-hydraulic parameters calculated for a scaled Rankine cycle without a turbine and using perfluorohexane as the simulant fluid is presented in Fig. 20. All the design parameters obtained for component sizes, power input requirements, and system temperatures appear to be practical from a manufacturing standpoint. It is hoped that such an experiment could initially be conducted aboard a microgravity aircraft flight 
and eventually make use of the FIR or similar facilities aboard the ISS, Space Shuttle, or other vehicle capable of providing long-duration low-gravity conditions.

Further work will be needed to arrive at a detailed design for the scaled loop experiment. During the detailed design process, it will be necessary to examine the possible influence of several factors not considered in this scaling study, including the thermal conductivity and wetting behavior of the helical boiler insert as well as any secondary circumferential flows of liquid around the tube walls and insert (which tend to violate the 1-D flow assumption used in the experiment scaling). It will also need to be confirmed analytically that the actual space Rankine cycle boiler and condenser design on which this scaling study was based is basically gravity independent.

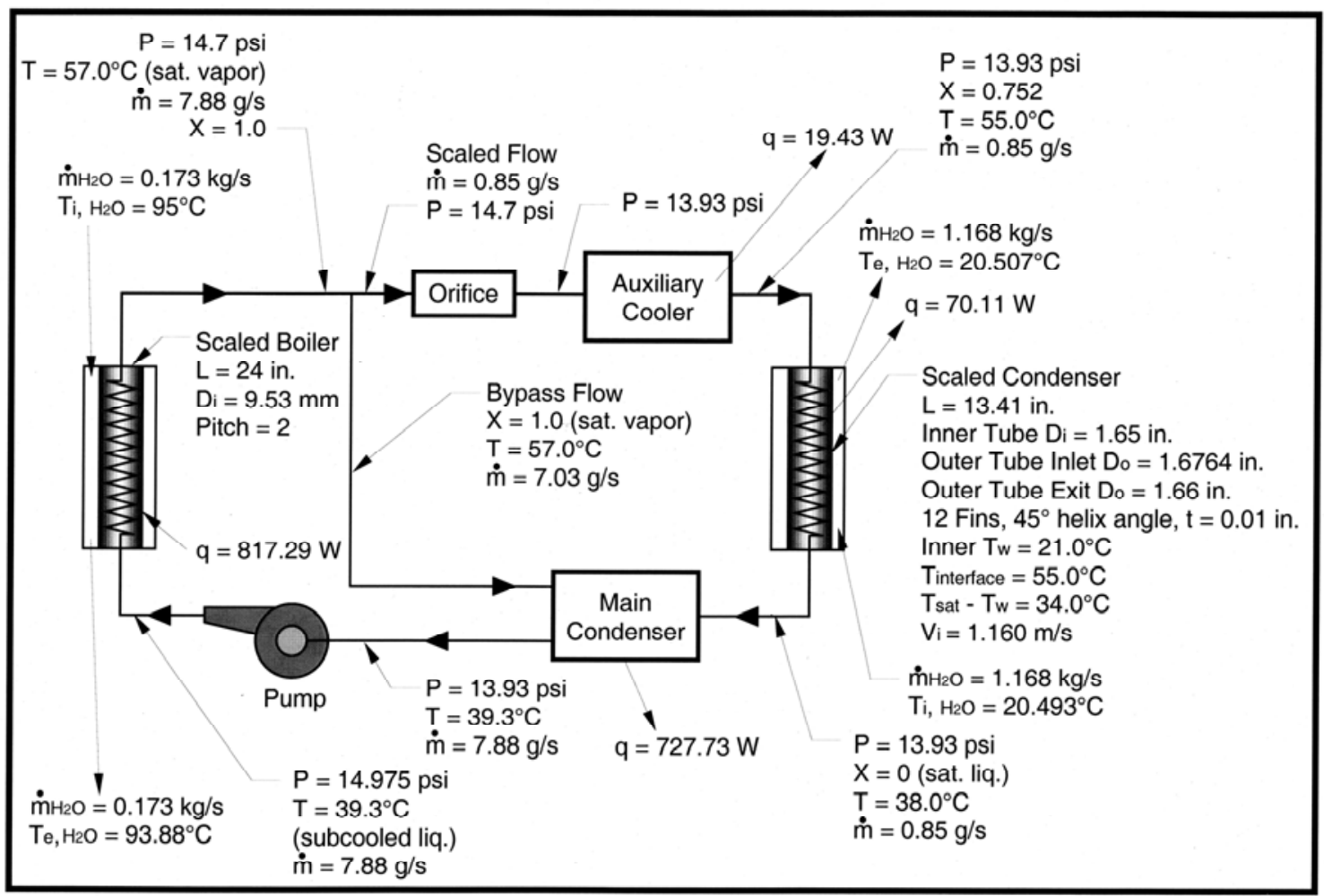

Fig. 20. Schematic diagram of complete scaled perfluorohexane loop experiment. 


\section{ESTIMATE OF DROPLET EVAPORATION RATES IN SUPERHEATED VAPOR}

As part of the design process for the scaled boiler, an estimate was needed on how long liquid droplets might be able to survive before evaporating when surrounded by a superheated vapor state. This information is important for the design of the instrumentation to measure any liquid carry-over at the boiler exit, because it helps set a minimum limit on the droplet size that needs to be detected. To assure dry vapor at the exit, the experimental setup must be sensitive enough to observe vapor droplets entrained in the flow down to a droplet diameter where the residence time is negligibly short.

An estimate of the droplet evaporation time can be obtained by considering the situation in Fig. 21, where a liquid droplet of radius $\mathrm{R}$ and temperature $\mathrm{T}_{\text {sat }}$ is suspended in an effectively infinite volume of superheated vapor at some $\mathrm{T}_{\infty}>\mathrm{T}_{\text {sat }}$.

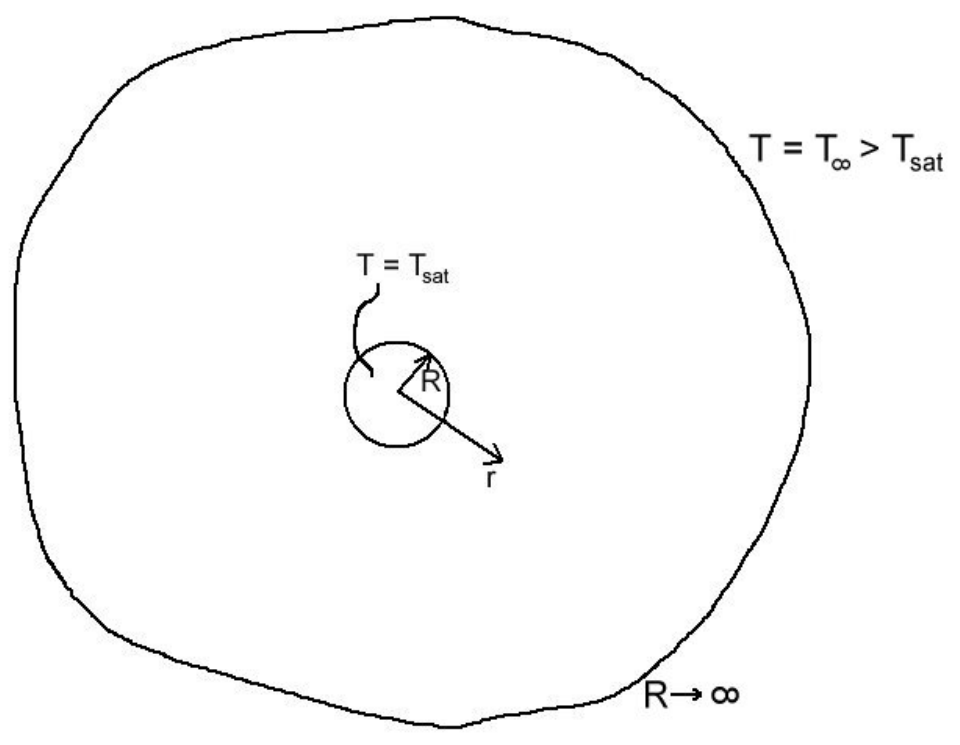

Fig. 21. Schematic diagram for developing the droplet evaporation equations. yields 5

Writing the steady-state form of the heat conduction equation within the vapor region

$$
\mathrm{d} / \mathrm{dr}\left(-\mathrm{k}_{\mathrm{v}} 4 \pi \mathrm{r}^{2} \mathrm{dT} / \mathrm{dr}\right)=0
$$

where $\mathrm{k}_{\mathrm{v}}$ is the vapor thermal conductivity. This analysis neglects any convective effects in the vapor, but it should set a lower limit on the heat transfer rate to the liquid droplet. Defining $\theta=$ $\mathrm{T}-\mathrm{T}_{\text {sat }}$ and simplifying gives

$$
\mathrm{d} / \mathrm{dr}\left(\mathrm{r}^{2} \mathrm{~d} \theta / \mathrm{dr}\right)=0
$$

which must be solved subject to the boundary conditions $\theta(r=R)=0$ and $\theta(r \rightarrow \infty)=T_{\infty}-T_{\text {sat }}$ to determine the temperature profile in the vapor. The resulting solution for the vapor temperature profile is then

$$
\theta(r)=\left(T_{\infty}-T_{\text {sat }}\right)[1-R / r] .
$$


Now the radial heat transfer rate at the surface of the liquid drop can be related to the vapor temperature profile by

$$
\mathrm{q}_{\mathrm{r}}(\mathrm{r}=\mathrm{R})=-4 \pi \mathrm{R}^{2} \mathrm{k}_{\mathrm{v}}(\mathrm{d} \theta / \mathrm{dr})_{\mathrm{r}=\mathrm{R}}=-4 \pi \mathrm{R} \mathrm{k}_{\mathrm{v}}\left(\mathrm{T}_{\infty}-\mathrm{T}_{\mathrm{sat}}\right) .
$$

Furthermore, the heat flow into the drop implies a rate of change in droplet mass because

$$
\left|\mathrm{q}_{\mathrm{r}}(\mathrm{r}=\mathrm{R})\right|=-\mathrm{h}_{\mathrm{fg}} \mathrm{dm} / \mathrm{dt} \text { and } \mathrm{dm} / \mathrm{dt}=4 \pi \mathrm{R}^{2} \rho_{\mathrm{l}} \mathrm{dR} / \mathrm{dt}
$$

where $h_{f g}$ is the enthalpy of vaporization for the liquid and $\rho_{l}$ is the liquid density. Combining these equations gives

$$
4 \pi R k_{v}\left(T_{\infty}-T_{\text {sat }}\right)=-4 \pi R^{2} \rho_{l} h_{f g} d R / d t
$$

Simplifying this equation algebraically and integrating it from $r=R$ down to $r=0$ allows one to solve for the time, $t_{\text {evap }}$, needed to evaporate the droplet:

$$
t_{\text {evap }}=\left[R^{2} \rho_{l} h_{f g}\right] /\left[2 k_{v}\left(T_{\infty}-T_{\text {sat }}\right)\right] .
$$

For the selected FC-72 scaled boiler design, the exit pressure is at atmospheric so that $\mathrm{k}_{\mathrm{V}}=$ $11.3 \times 10^{-3} \mathrm{~W} / \mathrm{m} \mathrm{K}, \mathrm{h}_{\mathrm{fg}}=84510.9 \mathrm{~J} / \mathrm{kg}$, and $\rho_{\mathrm{l}}=1619.73 \mathrm{~kg} / \mathrm{m}^{3}$ with a vapor exit velocity of $8.25 \mathrm{~m} / \mathrm{s}$. If one assumes a droplet of diameter of $10^{-6} \mathrm{~m}$ and about $5^{\circ} \mathrm{C}$ of vapor superheat, it follows that the survival time $t_{\text {evap }}=3.03 \times 10^{-4} \mathrm{~s}$. The corresponding transit distance downstream is then given by

$$
\Delta \mathrm{z}=3.03 \times 10^{-4} \mathrm{~s}(8.25 \mathrm{~m} / \mathrm{s})=2.50 \mathrm{~mm},
$$

which is negligible compared to the overall boiler tube length of 24.0 in. Hence optical instrumentation capable of verifying that there are no liquid droplets larger than $10^{-6} \mathrm{~m}$ in diameter at the scaled boiler exit should provide high confidence that pure FC-72 vapor is being supplied to the remainder of the experimental loop. 


\section{CONCLUSIONS}

This report has set forth a scaling procedure for design of an experiment to represent the thermal-hydraulic behavior of a space-based Rankine cycle system. It also describes the most promising preconceptual design parameters for such a scaled boiler and condenser system using FC-72 as the working fluid. The system selected appears to be the best possible compromise in terms of both scaling accuracy for the boiler and condenser to the actual potassium Rankine cycle design and convenience in conducting the experiment. The scaled boiler tube and condenser can be integrated into a single experimental system by incorporating a pump, main condenser, orifice, and auxiliary cooler into the loop. All the preconceptual design parameters seem practical from a fabrication and experimental standpoint, but further work will be needed to arrive at a final experiment design.

Additional areas that need to be resolved in the final design include the precise fabrication methods required for twisting an aluminum strip to produce the helical insert and the bonding techniques needed to secure the insert inside the Pyrex boiler tube. Thermal analysis of the bond between the tube and twisted tape will be very important to determine the radial temperature profile across the twisted tape and its effect on boiling conditions. Bonding of the plastic pieces to the copper condenser core also may need to be investigated. Finally, a CFD analysis of the FC-72 flows in the inlet and outlet manifolds may be necessary to predict the pressure drop across the condenser assembly. 


\section{REFERENCES}

1. R. W. Fox and A. T. McDonald, Introduction to Fluid Mechanics, 3rd Ed., John Wiley \& Sons, New York, 1985.

2. J. R. Peterson, High-Performance "Once-Through" Boiling of Potassium in Single Tubes at Saturation Temperatures of $1500^{\circ}$ to $1750^{\circ} \mathrm{F}$, NASA CR-842, National Aeronautics and Space Administration, Washington, D.C., 1967.

3. G. L. Yoder, Jr., J. J. Carbajo, R. W. Murphy, A. L. Qualls, C. D. Sulfredge, M. P. Moriarty, F. J. Widman, K. J. Metcalf, and M. Nikitkin, Technology Development Program for an Advanced Potassium Rankine Power Conversion System Compatible with Several Space Reactor Designs, Final Phase I Report, ORNL/TM-2004/214, Oak Ridge National Laboratory, Oak Ridge, Tennessee, September 2004.

4. J. E. Fredley and C. E. Braun, "A Low Pressure Drop Heat Exchanger with Integral Heat Pipe," Proceedings of the 1988 ASME National Heat Transfer Conference, Houston, Texas, July 24-27, 1988.

5. V. P. Carey, Liquid-Vapor Phase-Change Phenomena, Hemisphere, Washington, D.C., 1992.

6. F. P. Incropera and D. P. DeWitt, Fundamentals of Heat and Mass Transfer, 3rd Ed., John Wiley \& Sons, New York, 1990.

7. Personal communication with Andrew Sexton, NASA QSS Group, Inc., March 21, 2005. 